\title{
SAMHD1 is active in cycling cells permissive to HIV-1 infection
}

\author{
Roger Badia ${ }^{\text {, }}$, Maria Pujantell ${ }^{\text {a }}$, Javier Torres-Torronteras ${ }^{\text {b }}$, Luis Menéndez-Arias ${ }^{\text {, }}$, \\ Ramón Martí ${ }^{\mathrm{b}}$, Albert Ruzo ${ }^{\mathrm{d}}$, Eduardo Pauls ${ }^{\mathrm{a}}$ e ${ }^{\text {, }}$, Bonaventura Clotet ${ }^{\mathrm{a}}$, Ester Ballana ${ }^{\mathrm{a}}$, \\ José A. Esté ${ }^{\text {a, }}$, Eva Riveira-Muñoz ${ }^{\text {a, *** }}$ \\ a AIDS Research Institute - IrsiCaixa and Health Research, Institute Germans Trias i Pujol (IGTP), Hospital Germans Trias i Pujol, Universitat Autònoma de \\ Barcelona, Badalona, Spain \\ ${ }^{\mathrm{b}}$ Research Group on Neuromuscular and Mitochondrial Disorders, Vall d'Hebron Institut de Recerca, Universitat Autònoma de Barcelona, Biomedical \\ Network Research Centre on Rare Diseases (CIBERER), Instituto de Salud Carlos III, Spain \\ " Centro de Biología Molecular "Severo Ochoa", Consejo Superior de Investigaciones Científicas, Universidad Autónoma de Madrid, Madrid, Spain \\ d Laboratory of Molecular Embryology, The Rockefeller University, New York, NY, USA \\ e Joint IRB-BSC-CRG Program in Computational Biology, Institute for Research in Biomedicine, The Barcelona Institute of Science and Technology, Barcelona, \\ Catalonia, Spain
}

\section{A R T I C L E I N F O}

\section{Article history:}

Received 10 November 2016

Received in revised form

24 February 2017

Accepted 25 March 2017

Available online 28 March 2017

\section{Keywords:}

CRISPR

Genome editing

SAMHD1

dNTPase activity

\begin{abstract}
A B S T R A C T
SAMHD1 is a triphosphohydrolase that restricts HIV-1 by limiting the intracellular dNTP pool required for reverse transcription. Although SAMHD1 is expressed and active/unphosphorylated in most cell lines, its restriction activity is thought to be relevant only in non-cycling cells. However, an in depth evaluation of SAMHD1 function and relevance in cycling cells is required. Here, we show that SAMHD1-induced degradation by HIV-2 Vpx affects the dNTP pool and HIV-1 replication capacity in the presence of the 3'-azido-3'-deoxythymidine (AZT) in cycling cells. Similarly, in SAMHD1 knockout cells, HIV-1 showed increased replicative capacity in the presence of nucleoside inhibitors, especially AZT, that was reverted by re-expression of wild type SAMHD1. Sensitivity to non-nucleoside inhibitors (nevirapine and efavirenz) or the integrase inhibitor raltegravir was not affected by SAMHD1. Combination of three mutations (S18A, T21A, T25A) significantly prevented SAMHD1 phosphorylation but did not significantly affect HIV1 replication in the presence of AZT. Our results demonstrate that SAMHD1 is active in HIV-1 permissive cells, does not modify susceptibility to HIV-1 infection but strongly affects sensitivity to nucleoside inhibitors.
\end{abstract}

(c) 2017 Elsevier B.V. All rights reserved.

\section{Introduction}

Sterile alpha motif and histidine-aspartate domain-containing protein 1 (SAMHD1) is a deoxynucleoside triphosphate triphosphohydrolase (Goldstone et al., 2011; Lahouassa et al., 2012) (reviewed in (Pauls et al., 2013; Schaller et al., 2012)) described as a restriction factor for RNA and DNA viruses. The restriction activity of SAMHD1 has been described for other retroviruses such as feline immunodeficiency virus (FIV), simian immunodeficiency virus (SIV) and equine infectious anemia virus (EIAV) (Gramberg et al., 2013), but also in human T-cell lymphotropic virus (HTLV-1) (Sze et al., 2013a), hepatitis B virus (HBV) (Chen et al., 2014; Sommer et al., 2016) and DNA virus such as vaccinia or herpes simplex type 1 (HSV-1) (Badia et al., 2016a; Hollenbaugh et al., 2013; Kim et al., 2013). SAMHD1 restricts HIV-1 replication in resting T cells and non-cycling myeloid cells (Baldauf et al., 2012; Hrecka et al., 2011; Laguette et al., 2011). SAMHD1 restriction is counteracted by HIV-2 and related simian immunodeficiency viruses (SIVsm/ $\mathrm{mac}$ ) virion-associated Vpx accessory proteins (Vpx) by loading SAMHD1 onto the CRL4(DCAF1) E3 ubiquitin ligase, leading to highly efficient proteasome-dependent degradation of the protein (Hrecka et al., 2011). The activity of SAMHD1 as a viral restriction factor has been recently reviewed in (Ballana and Este, 2015; Rice and Kimata, 2015; Simon et al., 2015).

\footnotetext{
* Corresponding author. IrsiCaixa, Hospital Germans Trias i Pujol, C. Canyet s/n, 08916 Badalona, Spain.

** Corresponding author. IrsiCaixa, Hospital Germans Trias i Pujol, C. Canyet s/n, 08916 Badalona, Spain.

E-mail addresses: jaeste@irsicaixa.es (J.A. Esté), eriveira@irsicaixa.es (E. Riveira-Muñoz).
} 
The observation that SAMHD1 does not restrict HIV-1 in cycling cells (Baldauf et al., 2012; Descours et al., 2012) indicated a close relationship between a functional SAMHD1 and a state of reduced metabolic activity. The regulation of the size of the intracellular dNTP pool through the dNTPase function of SAMHD1 was initially suggested to be responsible for the blocking of HIV-1 reverse transcription (RT) (Lahouassa et al., 2012). Alternative mechanisms involving DNA and RNA endonuclease activity have been proposed (Ryoo et al., 2014) but challenged severely (Antonucci et al., 2016; Seamon et al., 2015). SAMHD1 activity is tightly linked to the regulation and the progression of the cell cycle, as cyclindependent kinases 1 and 2 (CDK1/2) have been shown to inactivate SAMHD1 through phosphorylation (Pauls et al., 2014b, 2014c; Ruiz et al., 2015; Yan et al., 2015) (Cribier et al., 2013; White et al., 2013b), CDK2 (Pauls et al., 2014b; Ruiz et al., 2015; St Gelais et al., 2014) and therefore those kinases play a pivotal role in SAMHD1 regulation and viral restriction.

Although Phosphorylation of SAMHD1 at T592 is accepted as a marker of SAMHD1 inactivation due to the loss of viral restriction capacity (Cribier et al., 2013; Welbourn et al., 2013; White et al., 2013b; Wittmann et al., 2015) it does not correlate with a decrease in its phosphohydrolase activity in vitro (Arnold et al., 2015; Tang et al., 2015). Different hypotheses emerged to explain this apparent contradiction, including the existence of a SAMHD1associated ribonuclease (RNase) activity (Ryoo et al., 2014), the compartmentalization of unphosphorylated (active) and phosphorylated (inactive) forms of the enzyme (Brandariz-Nunez et al., 2012) or the association of phosphorylated forms of SAMHD1 with an unidentified repressor, cyclin L2 (Kyei et al., 2015) or cyclin D2 (Badia et al., 2016b). However, elucidating the mechanism of action of SAMHD1 has been obscured by the use of distinct and heterogeneous models of stable cell lines with differential SAMHD1 expression or activation, under cell cycle control by different CDK or with considerably different dNTP levels (Ballana and Este, 2015).

Here, we describe a CRISPR/Cas9 system to generate cycling cells without (knockout) or reduced (knockdown) levels of SAMHD1 to evaluate the effect of SAMHD1 activity on intracellular dNTP levels and HIV-1 restriction capacity. Evaluation of viral replication in SAMHD1 knockout cells in the presence of nucleoside reverse transcriptase inhibitors (NRTIs), revealed that SAMHD1 function is maintained in cycling cells and suggests that modifications of the dNTPs intracellular pool and enhances SAMHD1 tryphosphohydrolase activity, an effect that is responsible for HIV-1 restriction.

\section{Materials and methods}

\subsection{Cells}

The human cell lines MT-4, TZMbl, THP1 and HEK293T were obtained from NIH AIDS Reagent Program, National Institutes of Health (Bethesda, MD, USA). MT-4 cell line was grown in RPMI 1640 medium, supplemented with $10 \%$ of heat-inactivated fetal calf serum (FCS, Gibco, Life Technologies) and antibiotics $100 \mathrm{U} / \mathrm{ml}$ penicillin, $100 \mu \mathrm{g} / \mathrm{ml}$ streptomycin (Life Technologies). TZMbl and HEK293T cells were maintained in DMEM (Gibco) supplemented with $10 \% \mathrm{FCS}, 100 \mathrm{U} / \mathrm{ml}$ penicillin, $100 \mu \mathrm{g} / \mathrm{ml}$ streptomycin and maintained at $37^{\circ} \mathrm{C}$ in a $5 \% \mathrm{CO}_{2}$ incubator. When needed, THP1 cells were treated with $10 \mathrm{ng} / \mathrm{ml}$ of phorbol 12-myristate 13-acetate (PMA) for $24 \mathrm{~h}$.

Peripheral blood mononuclear cells (PBMC) were obtained from buffy coats of blood of healthy donors using a Ficoll-Paque density gradient centrifugation and monocytes were purified using negative selection antibody cocktails (StemCell Technologies). Monocytes were cultured as described before (Pujantell et al., 2016). Briefly, cell were maintained in complete culture medium (RPMI
1640) medium supplemented with $10 \%$ heat-inactivated fetal bovine serum (FBS; Gibco) and penicillin/streptomycin (Gibco) and differentiated to monocyte derived macrophages (MDM) for 4 days in the presence of monocyte-colony stimulating factor (M-CSF, Peprotech) at $100 \mathrm{ng} / \mathrm{ml}$. The protocol was approved by the scientific committee of Fundació IrsiCaixa. Buffy coats were purchased from the Catalan Banc de Sang i Teixits (http://www.bancsang.net/ en/index.html).

\subsection{Compounds}

3-Azido-3-deoxythymidine (zidovudine, AZT) was purchased from Sigma-Aldrich (Madrid, Spain). Stavudine (d4T), lamivudine (3TC), zalcitabine (ddC), didanosine (ddI), tenofovir disoproxil fumarate (TFV), efavirenz (EFV), and nevirapine (NVP) were obtained from the NIH AIDS Research and Reference Reagent Program. Abacavir (ABC) was purchased from Selleckchem (Munich, Germany). The integrase inhibitor raltegravir (RAL) was provided by Merck Sharp and Dome, Spain. All compounds were resuspended in DMSO and stored at $-20^{\circ} \mathrm{C}$ until use.

\subsection{Generation of CRISPR-Cas9 targeting SAMHD1}

Synthesis of CRISPR-Cas9 targeting SAMHD1 (CRISPR SAMHD1) gene was performed using the plasmid PX330-U6-chimeric $\mathrm{BB}+8 \mathrm{e} 5-\mathrm{CBh}-\mathrm{eGFP}-\mathrm{Puromycin-Cas9.}$ Briefly, CRISPRSAMHD1 was designed to disrupt the sequence corresponding to exon 5 of SAMHD1 gene that encodes for HD domain (Fig. 2A), responsible of nucleotidase and phosphodiesterase activities of the SAMHD1 protein. The gRNA sequence (forward 5'-GGATGTCTAGTTCACGCACT-3'; reverse 5'- AGTGCGTGAACTAGACATCC-3') was determined with the CRISP design online platform (http://crispr.mit.edu/ ) .

\subsection{Generation of SAMHD1 knockout cells}

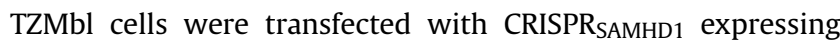
plasmid as described previously (Badia et al., 2014b). Briefly, $1.5 \times 10^{5}$ cells were seeded in 24 well plates. After overnight cul-

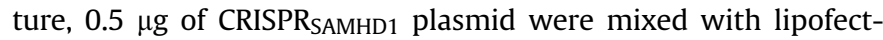
amine 2000 reagent (Invitrogen) in serum-free medium OptiMEM (Invitrogen) and then added to previously washed cells. Media was replaced by fresh DMEM, four hours after transfection, and left in the incubator for 3 days. Cells were treated with puromycin $(1 \mu \mathrm{g} /$ $\mathrm{ml}$ ) for $24 \mathrm{~h}$. After puromycin selection, single cell clones were obtained by limiting dilution in 96 -well plates.

\subsection{Analysis of genome editing}

Pre-screening of genome editing of SAMHD1 in the different clones was evaluated by the determination of heteroduplex for-

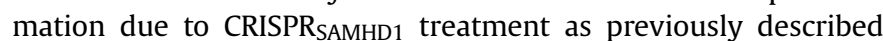
(Badia et al., 2014a, 2014b). Briefly, editing efficiency was estimated

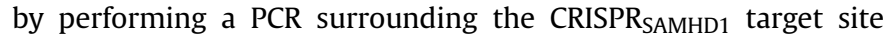
followed by digestion with $0.5 \mu \mathrm{l}$ T7 endonuclease (New England Biolabs), which cleaves DNA heteroduplex at mismatched sites. Generated fragments were resolved by $2 \%$ agarose electrophoresis as previously described (Badia et al., 2014a, 2014b).

Clones were selected according to their heteroduplex profile for further sequence analysis of edited region of SAMHD1. Briefly, genomic DNA from sorted single cells clones was extracted using the QIAamp DNA Blood Mini Kit (Qiagen). Extracted DNA was used to amplify the SAMHD1 gene using Expand High Fidelity PCR System (Roche) and the following primers (forward 5'TTTTGGGATTCCGTTTGTGT-3' and reverse 5'-TCACTGAAAGTTGCCA 
AGAAAA-3'). PCR products were cloned into the pGEM-T Easy Vector System (Promega) according to the manufacturer's instructions. Plasmid sequencing was carried out by the Macrogen Genomic Division, Seoul, Korea using ABI PRISM Big Dye TM Terminator Cycle Sequencing technology (Applied BioSystems). Sequences were analyzed with the Sequencher 4.5 software (Gene Codes Corporation, Ann Arbor, MI, USA).

\subsection{Intracellular SAMHD1 staining by flow cytometry}

Cells were fixed for 20 min with $4 \%$ formaldehyde (FA) followed by permeabilization for 15 min with $0.5 \%$ Triton X-100 in PBS. After incubation for $1 \mathrm{~h}$ in phosphate buffered saline (PBS) containing $2 \%$ bovine serum albumin (BSA), cells were stained with the rabbit polyclonal anti-SAMHD1 (1:100, catalog no. 12586-1-AP; Proteintech) for $1 \mathrm{~h}$ followed by incubation for $20 \mathrm{~min}$ with the goat anti-rabbit Alexa 633 antibody (1:1000; Life Technologies), both diluted in the Blocking medium. Flow cytometry was performed in a FACS LSRII flow cytometer (BD Biosciences). Data were analyzed using the FlowJo software (Single Cell Analysis Software).

\subsection{Western blot}

Treated cells were rinsed in ice-cold PBS, extracts were prepared in lysis buffer (50 mM Tris $\mathrm{HCl}$ pH 7.5, $1 \mathrm{mM}$ EDTA, $1 \mathrm{mM}$ EGTA, $1 \mathrm{mM} \mathrm{NaV} \mathrm{O}_{4}, 10 \mathrm{mM}$ sodium $\beta$-glycerophosphate, $50 \mathrm{mM} \mathrm{NaF}$, $5 \mathrm{mM}$ sodium pyrophosphate, $270 \mathrm{mM}$ sucrose and $1 \%$ Triton X100) supplemented with protease inhibitor cocktail (Roche) and $1 \mathrm{mM}$ phenylmethylsulfonyl fluoride. Samples were electrophoresed in SDS-polyacrylamide gels containing 6-10\% acrylamide, and blotted onto nitrocellulose membranes. Blocked membranes were incubated overnight at $4{ }^{\circ} \mathrm{C}$ with the following antibodies: anti-rabbit and anti-mouse horseradish peroxidaseconjugated secondary antibodies (1:5000; Pierce); anti-human Hsp90 (1:1000; 610418, BD Biosciences); anti-SAMHD1 (1:2500; ab67820, Abcam); anti-phospho(Thr)-Pro (ref. 23,21), phosphoCDK2 (Thr160; ref. 2561), anti-CDK2 (ref. 2546) and anti-CDK1 (ref. 9116) (all 1:1000; Cell Signalling Technologies) and anti $\beta$ Actin (1:5000; ref. A5316, Sigma-Aldrich). Anti-phospho-SAMHD1 Thr592 (pSAMHD1 T592) was obtained by immunization of rabbit using a phosphorylated peptide as described before (White et al. 2013b). After washing, the membranes were incubated with a secondary conjugated horseradish peroxidase antibody for $1 \mathrm{~h}$ at room temperature and then revealed with SuperSignal West Pico Chemiluminescent Substrate (Pierce Chemical, Rockford, IL, USA).

\subsection{Generation of SAMHD1 phosphorylation defective mutants}

Phosphorylation defective mutants were generated using Quick Change Lightning site-directed mutagenesis kit (Agilent technologies), according to manufacturer's instructions. Briefly, serines at positions 18 and 33 and threonines at positions 21, 25 and 592 were replaced by alanines (S18A, T21A, T25A, S33A and T592A). A mutant plasmid encoding amino acid substitutions S18A, T21A, T25A (triple mutant; 3T) was also generated. Wild-type and phosphorylation defective mutants variants of SAMHD1 were cloned into pLPCX plasmid (Clontech Laboratories). All introduced mutations were confirmed by DNA sequencing. For transient re-expression of wildtype and phosphorylation defective mutants of SAMHD1 in TZMbl knock-out cells, $0.5 \mu \mathrm{g}$ of each plasmid was transfected with lipofectamine 2000 reagent (Invitrogen) in serum-free medium OptiMEM (Invitrogen) and then added to previously washed cells. Media was replaced by fresh DMEM $4 \mathrm{~h}$ after transfection and left in the incubator for 3 days before infection and drug sensibility assays.

\subsection{Evaluation of ATP degradation in vitro by SAMHD1}

For the assessment of the tryphosphohydrolase activity of SAMHD1 in vitro, we used a SAMHD1-HA construct, kindly provided by Philip Cohen (Medical Research Council Protein Phosphorylation and Ubiquitylation Unit, Dundee, U.K.). Briefly, the SAMHD1-HA expression plasmid was transfected in HEK 293T cells and lysates obtained 3 days post-transfection. SAMHD1-HA was immunoprecipitated from $1 \mathrm{mg}$ of lysate using HA-beads as previously described (Pauls et al., 2014b), washed and incubated or not in the presence of phosphatase lambda for $1 \mathrm{~h}$ at $37^{\circ} \mathrm{C}$. Beads were washed and incubated with $1 \mathrm{mM}$ dATP in the absence or presence of $1 \mathrm{mM}$ dGTP at $37{ }^{\circ} \mathrm{C}$ during the indicated times. Activity of SAMHD1 was evaluated using the ATP Assay Kit (Merck Millipore) according to the manufacturer's instructions.

\subsection{Virus and infections}

The envelope-deficient HIV-1 NL4-3 clone encoding internal ribosome entry site (IRES)-green fluorescent protein (GFP) (NL4-3GFP) was pseudotyped with vesicular stomatitis virus $G$ protein (VSV-G) by cotransfection of HEK293T cells using polyethylenimine (Polysciences) as previously described (Pauls et al., 2014b). The HIV-1 viral strain NL4-3 (X4-tropic) was obtained from the NIBSC Centre for AIDS Reagents (CFAR, London, UK). NL4-3 strain was grown in lymphoid MT-4 cell line. Viral stocks were titrated for its use in MT-4 and TZMbl cells respectively. For the production of viral-like particles carrying Vpx (VLPVpx), HEK293T cells were cotransfected with pSIV3+ (Mangeot et al., 2000) and a VSV$\mathrm{G}$-expressing plasmid. Three days after transfection, supernatants were harvested, filtered, and stored at $-80^{\circ} \mathrm{C}$.

For infections in TZMbl cells, $1.5 \times 10^{4}$ cells were seeded in 96well plates and infected with HIV-1 NL4-3 or VSV-pseudotyped NL4-3 GFP-expressing virus. Reverse transcriptase inhibitors AZT, d4T, 3TC, ddC, ddI, TDF, ABC, EFV and NVP and the integrase inhibitor RAL were used as controls. Measurement of infection by HIV-1 NL4-3 was determined by the $\beta$-galactosidase colorimetric assay as described elsewhere (Badia et al., 2014a). Briefly, cells were lysed $72 \mathrm{~h}$ after infection and kept frozen until analysis. $\beta$-galactosidase activity in $30 \mu \mathrm{L}$ cell extracts was quantified by Absorbance $(405-620 \mathrm{~nm})$ of non-infected samples was subtracted from the rest of samples and values expressed as percentage of $\beta$-galactosidase activity relative to non-drug treated control.

Assessment of infection by VSV-NL43-GFP + virus was determined as the percentage of GFP + cells by flow cytometry (LSRII, BD Biosciences) $48-72 \mathrm{~h}$ after infection. Data were analyzed using the Flowjo software (Single Cell Analysis Software).

\subsection{Anti-HIV-1 and cytotoxicity assays in MT-4 cells}

MT-4 cells were pre-treated with viral Viral-like particles carrying Vpx (VLPVpx) produced as previously described (RiveiraMunoz et al., 2014) for $4 \mathrm{~h}$ before infection or left with fresh medium as a control. Cells were then infected with VSV-pseudotyped NL4-3-GFP + in the presence of nucleoside and non-nucleoside reverse transcriptase inhibitors AZT and NVP, respectively. Viral replication was measured two days later by flow cytometry as the number of GFP + cells, relative to the total number of cells. The anti-HIV activity of the different compounds was determined by infection of cells in the presence of different drug concentrations and toxicity of was quantified by a tetrazolium based colorimetric method [3-(4,5-dimethylthiazol-2-yl)-2,5-diphenyltetrazolium, MTT method] as previously described (Ballana et al., 2014) (Badia et al., 2015). 


\subsection{Determination of dNTP intracellular levels}

dNTP content was determined using a polymerase-based method as previously described (Ferraro et al., 2010; GonzalezVioque et al., 2011). Briefly, TZMbl cells were rinsed, counted and adjusted at $2 \times 10^{6}$ cells/sample. Then cells were lysed with trichloroacetic acid (TCA, $0.5 \mathrm{M}$ ). Cellular proteins were cleared by centrifugation and supernatants were neutralized with $0.5 \mathrm{M}$ Tri-noctylamine in 1,1,2-trichlorotrifluoroethane (Sigma-Aldrich). Aquose phases were recovered and dried in a SpeedVac. Pellets were resuspended in Tris- $\mathrm{HCl}$ buffer $(40 \mathrm{mM}, \mathrm{pH7.4})$ and the dNTP content determined using a polymerase-based method (Ferraro et al., 2010) with minor modifications. Briefly, $20 \mu \mathrm{L}$ of reaction mixture contained $5 \mu \mathrm{L}$ of dNTP extract in $40 \mathrm{mM}$ Tris- $\mathrm{HCl}, \mathrm{pH} 7.4$, $10 \mathrm{mM} \mathrm{MgCl} 2,5 \mathrm{mM}$ dithiothreitol, $0.25 \mu \mathrm{M}$ oligoprimer, $0.75 \mu \mathrm{M}$ [8- $\left.{ }^{3} \mathrm{H}\right] \mathrm{dATP}, 12-21 \mathrm{Ci} / \mathrm{mmol}$ (or [methyl $\left.{ }^{3} \mathrm{H}\right] \mathrm{dTTP}$ for the dATP assay) and 1.7 units of Thermo Sequenase DNA Polymerase (GE Healthcare). Reaction mixtures with aqueous dNTP standards were processed in parallel. After incubation at $48{ }^{\circ} \mathrm{C}$ for $60 \mathrm{~min}, 18 \mu \mathrm{L}$ of the mix was spotted on a Whatman DE81 paper and left to dry. The filters were washed 3 times for 10 min with $5 \% \mathrm{NaH}_{2} \mathrm{PO}_{4}$, once with water, once with absolute ethanol, and left to dry again. The retained radioactivity was determined by scintillation counting, and the amount of dNTP was calculated by interpolation on the calibration curves. To ensure the reliability of the results, duplicates of 2 different dilutions of each dNTP extract (usually undiluted and 1:3 water-diluted) were processed in each independent experiments.

\subsection{Statistical analyses}

Experimental data are presented as mean \pm SD. One-way ANOVA test was used for comparison between groups, using the GraphPad Prism software (GraphPad Software, San Diego, CA, USA). A $p$-value of 0.05 was considered statistically significant.

\section{Results}

3.1. HIV replication capacity was strongly affected by a SAMHD1mediated change in dNTP availability

The size of the dNTP pool was determined in MT-4 and TZMbl transformed cell lines in comparison with primary monocytederived macrophages (MDM) (i.e. GM-CSF and M-CSF derived macrophages). In MT- 4 and TZMbl cells, the dNTP levels were considerably high (Fig. 1A), ranging from 17-fold to 41-fold higher depending on each dNTP for MT-4 cells, or between 1.75-fold and 10.6-fold higher in TZMbl cells in comparison with MDMs.

To assess the triphosphohydrolase activity of SAMHD1 on viral replication, MT-4 cells were pre-treated with viral-like particles carrying Vpx (VLP $\mathrm{Vpx}_{\mathrm{X}}$ ) (Fig. 1B) prior to infection with VSV-HIV$\mathrm{GFP}^{+}$expressing virus in the presence of nucleoside and nonnucleoside reverse transcriptase inhibitors. SAMHD1 degradation induced by $\mathrm{VLP}_{\mathrm{Vpx}}$ resulted in higher intracellular dNTPs (Fig. 1C),
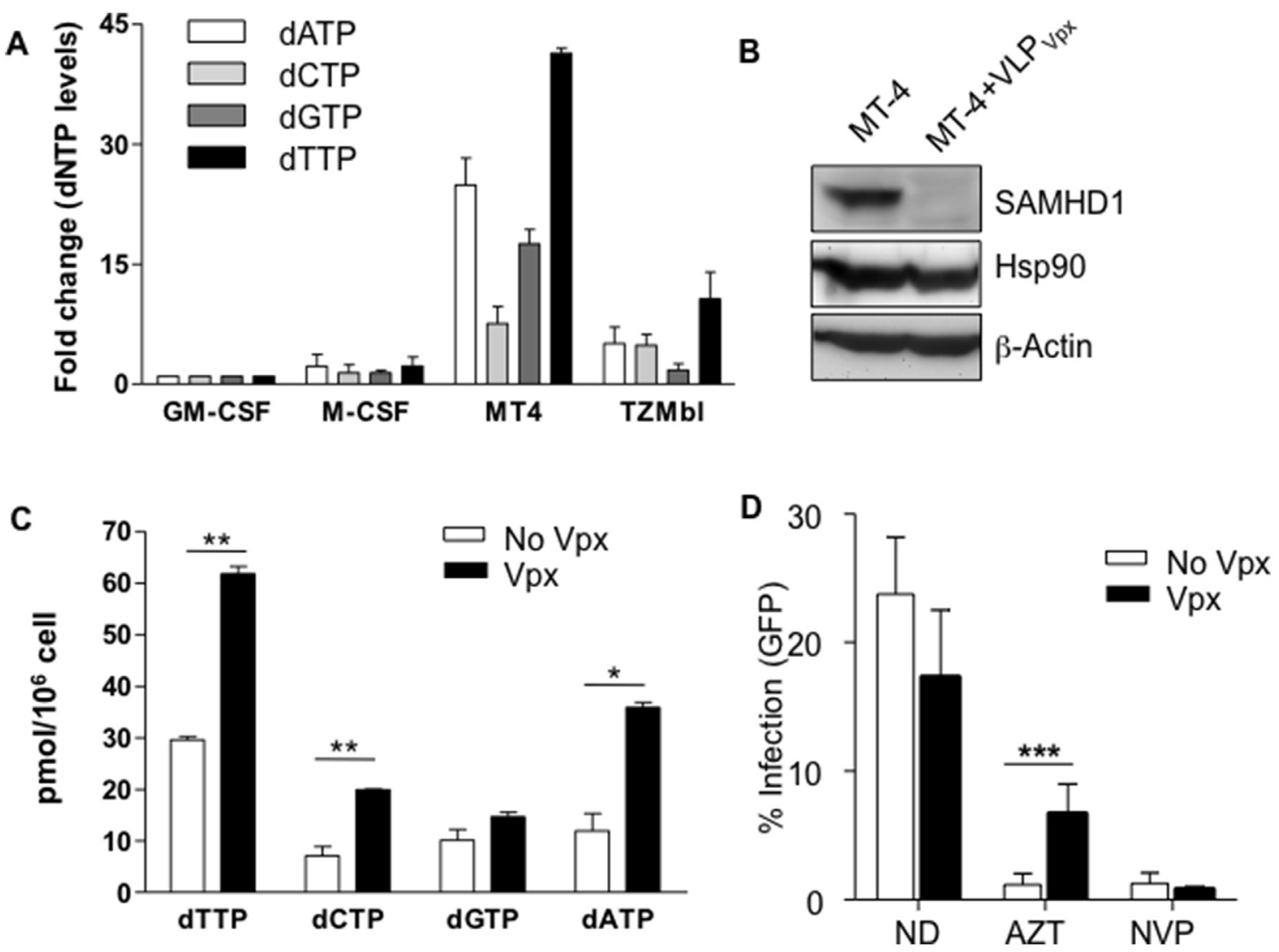

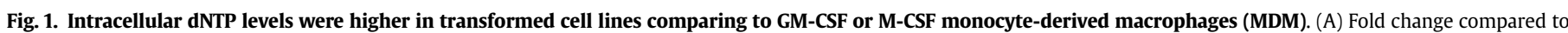

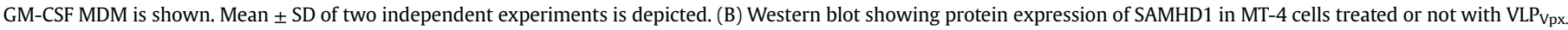

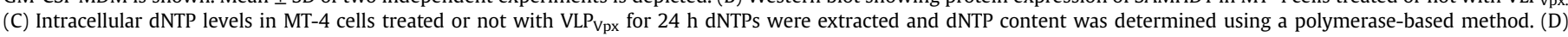

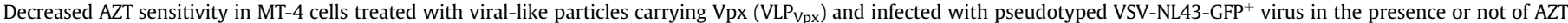

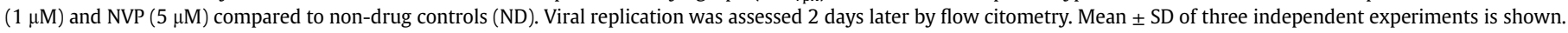
${ }^{*} p<0.05 ;{ }^{* *} p<0.01 ;{ }^{* * *} p<0.001$. 
ranging from to 2-fold increase for dTTP, 2.8-fold change for dCTP and 3.2-fold for dATP compared to the non-treated cells. A modest increase was observed for dGTP (1.5-fold). Infection of MT-4 treated with or without VLPVPx showed that SAMHD1 degradation induced by Vpx (Fig. 1D) did not boost HIV replication in VLPVpx pre-treated MT-4 cells compared to non-treated control. In the presence of the thymidine analogue AZT, viral replication was enhanced in MT4 cells expressing Vpx, showing a 5.7-fold increase compared to the control cells ( $p<0.001$ ) (Fig. 1D). Loss of sensitivity to AZT due to SAMHD1 degradation was specific for nucleoside analogues since no changes were observed in NVP-treated cells. Therefore, as previously observed (Amie et al., 2013; Ballana et al., 2014), the presence of a thymidine analogue such as AZT is required to assess the effects of SAMHD1 on the viral replication capacity in MT- 4 cells (Fig. 1C and D), due to the relatively high levels of intracellular dNTPs.

\subsection{Characterization and efficiency of the CRISPR $R_{S A M H D 1}$}

The time limited and transient effect of SAMHD1 degradation by VLP $_{\mathrm{Vpx}}$ in MT-4 cells, led us to generate SAMHD1 knockout cells for further characterization of the SAMHD1 tryphosphohydrolase activity. Therefore, CRISPR-Cas9 targeting SAMHD1 gene (CRISP$\mathrm{R}_{\mathrm{SAMHD} 1}$ ) was designed to specifically disrupt the exon 5 that encodes the HD domain (Fig. 2A), responsible of nucleotidase and phosphodiesterase activities of the SAMHD1 protein. Transformed cycling TZMbl cells were used in the following experiments due to the relatively feasibility to generate stable SAMHD1 knockout cell lines and their suitability to transfect and test all the different phosphorylation defective - SAMHD1 mutants. TZMbl cells were used instead of MT-4 cell line because the latter were originally transformed with human T-cell lymphotropic virus type 1 (HTLV-1) that induces improper DNA double strand break repair due to expression of the HTLV-1 Tax protein (Ducu et al., 2011), resulting in impaired cell survival of HTLV-1 transformed cell lines after genome editing by CRISPR endonucleases (data not shown).

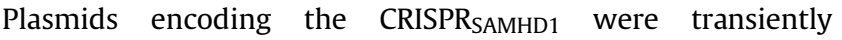
expressed in TZMbl cells in a single round of transfection and cells were cultured with $1 \mu \mathrm{g} / \mathrm{mL}$ of Puromycin (Life Technologies) for $24 \mathrm{~h}$, before isolating single-cell clones by limiting dilution. Then, cell culture plates were replicated and positive wells were prescreened for genetic modifications of the SAMHD1 gene. A total of 87 clones were analyzed by flow cytometry after intracellular staining for SAMHD1 (Fig. 2B): 15 clones (17.5\%) showed decreased levels of intracellular SAMHD1 protein (70\%-80\% reduction). Presumably, heterozygotic mutations for the SAMHD1 gene were observed in 35 clones (40.2\%), showing a 50\%-60\% reduction in SAMHD1 expression relative to the untreated TZMbl control cells. SAMHD1 levels above $70 \%$, and representing a wild-type phenotype were observed in $42.5 \%$ of the analyzed clones. Genetic modifications in pre-screened clones were confirmed by the evaluation of heteroduplex formation (Fig. 2C).

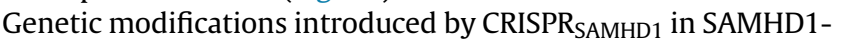
negative clones were characterized by cloning the coding region corresponding to the exon 5 of SAMHD1. Both deletions and insertions were identified, being deletions were more frequent than insertions and ranging from a $2 \mathrm{bp}$ deletion to a $220 \mathrm{bp}$ deletion and (Fig. 2D). According to the hypertriploid $(3 n+)$ nature of TZMbl (Landry et al., 2013), multiple sequences of SAMHD1 were identified for each selected clone, suggesting that multiples copies of SAMHD1 gene are present in the genome of TZMbl cells. However, CRISPR $_{\text {SAMHD } 1}$ effectively silenced SAMHD1 active copies for at least clones A2 and F5 (Fig. 2F). Therefore, CRISPR/Cas9 gene editing resulted in the generation of clones with different levels of SAMHD1 expression including functional SAMHD1 knockout (clones A2 and F5) and knockdown (clone C8) (Fig. 2E). Clones A2 and F5 did not show active or phosphorylated forms of SAMHD1 protein indicating a functional SAMHD1 knockout phenotype. In contrast, clone $\mathrm{G} 5$ retained reduced expression of both forms of the SAMHD1 protein. Clone C8 showed a band corresponding to very low levels of both active and phosphorylated forms of SAMHD1 so it was included in functional characterization experiments as

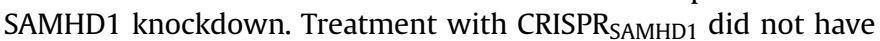
any effect on cyclin-dependent kinases 1 and 2 (CDK1, CDK2) believed to be responsible for regulation of SAMHD1 activity.

\subsection{Gene editing of SAMHD1 decreased antiviral potency of the thymidine analogue AZT}

We then evaluated the effect of SAMHD1 gene editing on its capacity to restrict HIV-1 NL4-3 infection in clones with functional knockout (clones A2 and F5) as compared to SAMHD1 knockdown (clone C8). Infections were performed in the presence of different concentrations of AZT using wild-type TZMbl as control. An AZT dose-dependent inhibition of infection was observed in all the clones tested (Fig. 3A). However, in knockout clones A2 and F5 HIV1 infection was not fully inhibited even at the highest AZT concentrations. Similar results were observed for clone C8 indicating

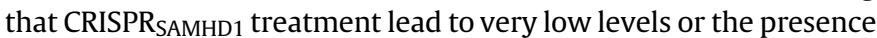
of truncated forms of SAMHD1 protein. Conversely, HIV-1 replication in wild-type cells and clone G5 were completely inhibited by

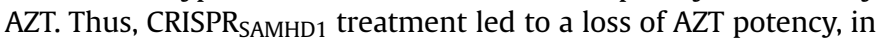
functional SAMHD1 knockout cells. The effect was specific for the thymidine nucleoside analogue as SAMHD1 knockout did not affect the sensitivity to the non-nucleoside reverse transcriptase inhibitor nevirapine or the integrase inhibitor raltegravir (Fig. 3B). Further assessment of the activity of NRTI in SAMHD1 knockout cells (clone F5) confirmed the decreased sensitivity to thymidine analogues (AZT and d4T) as well as for nucleoside analogues of guanosine (ABC) and adenosine (TDF and ddI) but not NNRTIs NVP or EFV (Table 1 ) in accordance to previously published results (Amie et al., 2013; Ballana et al., 2014).

Moreover, analysis of intracellular dNTPs revealed that CRISP$\mathrm{R}_{\mathrm{SAMHD} 1}$ treatment resulted in higher levels of dNTPs in clones A2, F5 and C8, ranging between 2 and 5-fold change depending on the nucleotide, compared to the untreated TZMbl cells and the G5 clone (Fig. 3C). Thus, permanent disruption of the SAMHD1 gene in TZMbl recapitulated the transient effect of $\mathrm{VLP}_{\mathrm{Vpx}}$ in MT-4 cells, providing a useful model to evaluate the activity of SAMHD1 in cycling cells.

\subsection{N-terminal SAMHD1 phosphorylation sites prediction in silico}

In addition to the previous described phosphorylation site at the residue T592, located at the C-terminal region of SAMHD1, we evaluated other potential sites susceptible to phosphorylation that might have a role on the regulation of SAMHD1 activity. Based on data provided by Phosphosite (http://www.phosphosite.org/) and previous published data using direct mass spectrometry (Welbourn et al., 2013) (White et al., 2013b), at least five phosphorylation sites have been described along the sequence of the SAMHD1 protein: 4 located at the N-terminus (S18, T21, T25, S33) and T592 at the Cterminus region of SAMHD1 (Fig. 4A). Phosphorylation defective mutants were constructed by site-directed mutagenesis and transfected into TZMbl cells. Single point mutations at the N-terminal region of SAMHD1 did not significantly affect the overall phosphorylation. However, the combination of mutations S18A, T21A and T25A (3T) significantly prevented the overall SAMHD1 phosphorylation as measured by the disappearance of the slow migrating band corresponding to the phosphorylated SAMHD1 (Fig. 4B), suggesting a major contribution to the overall SAMHD1 
A Homo sapiens SAM domain and HD domain 1(SAMHD1)

NG_017059.1 Chromosome 20

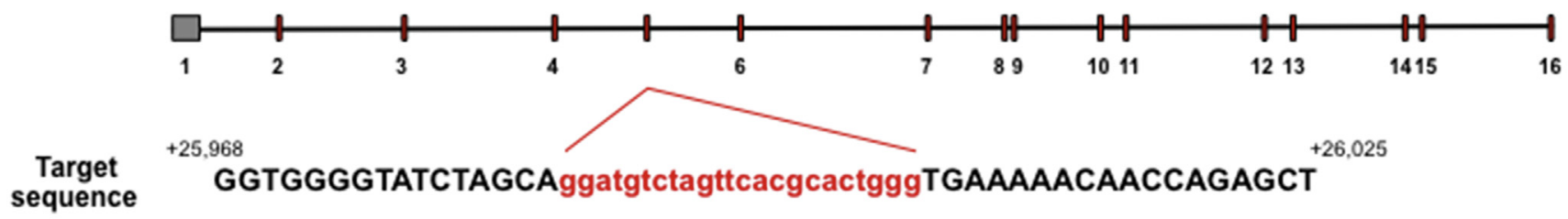

B
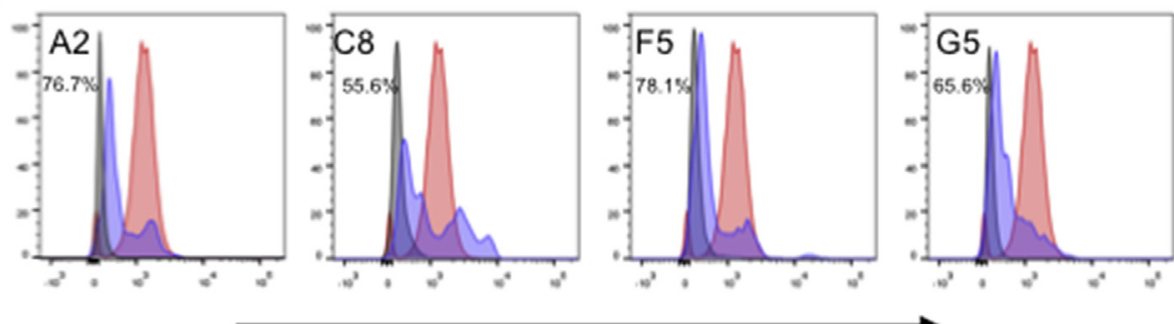

SAMHD1 - APC
C

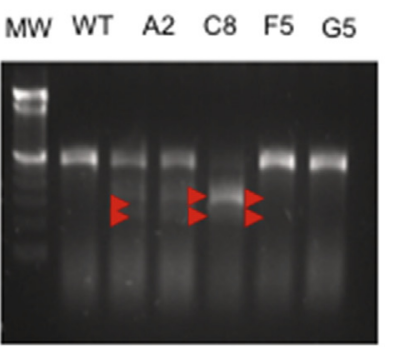

D

GGTGGGSTTCTAGCAGGATGTCTAGTTCACGCACTGGGTGAANACANCCAGAGCTGCAGATAGTGACGAGATGTICTCTGTGTTCAGATTGCTGGA X3

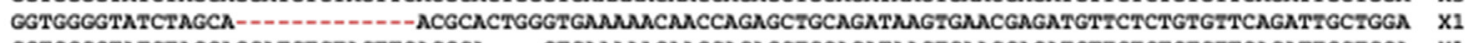
GGTGGCGTATCTAGCAGGATGTCTAGTTCACGCA----GTGAANAACACCAGAGCTGCAGATAATGAAGAGATGTTCTCTGTGTTCAGATIGCTGGA X1

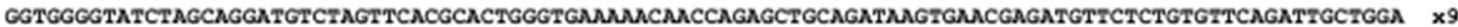

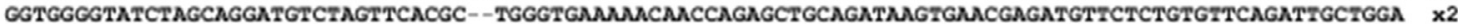

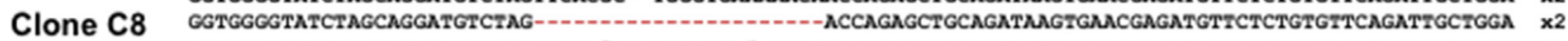
GGTGGGGTATCTAGCAGGATGTCTAGTT---\#Del 220 pb\#----ATGTACTGTTGCTTCTTCCTAGAATATTCATAAGTAGAAACATTGCTATTT X6 GGTGGGGTATCTAGCAGGATGTCTAGTTCACGCCACTGGGTGANAACANCAGAGCTGCAGATAATGAAGAGATGTTCTCTGTGTTCAGATTGCTGGA X1

GOTGGGTATCTAGCAGGATGTCTAGTTCACGCACTGGGTGNANACAMCCAGAGCTGCAGATAGTGACGAGATGTTCTCTGTGTTCAGATTGCTGGA X8 GGTGGGGTATCTAGCAGGATGTCTAG-------NCCAGAGCTGCAGATAATGACGAGATGTTCTCTGTGTTCAGATTGCTGGA X2

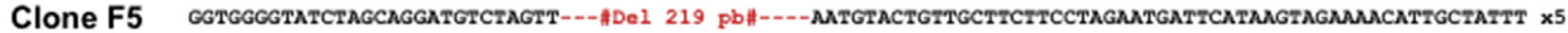
GGTGGGGTATCTAGCAGGATGTCTAGTTCACGCCACTGGGTGANAACAACAGAGCTGCAGATAAGTGACGAGATGTTCRCTGTGTTCAGATTGCTGGA X3 GGTGGGGTATCTAGCAGGATGTCTAGTTCACGCPACTGGGTGANAACA CCAGAGCTGCAGATAAGTGA CGAGATGTTCPCTGTGTTCAGATTGCTGGA X1

GGTGGGGTATCTAGCAGGATGTCTAGTTCACGCACTGGGTGAANACANCAGAGCTGCAGATAAGGACGAGATGTTCTCTGTGTTCAGATTGCTGGA X11

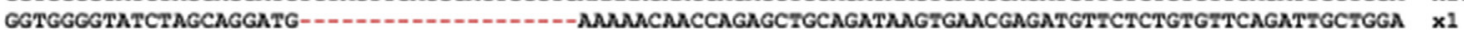
GGTGGGGTATCTAGCAGGATGTCTAGTTCACGCCACTGGGTGAANACAАCAGAGCTGCAGATAAGTGAACGAGATGTCTCTGTGTTCAGATTGCTGGA X1

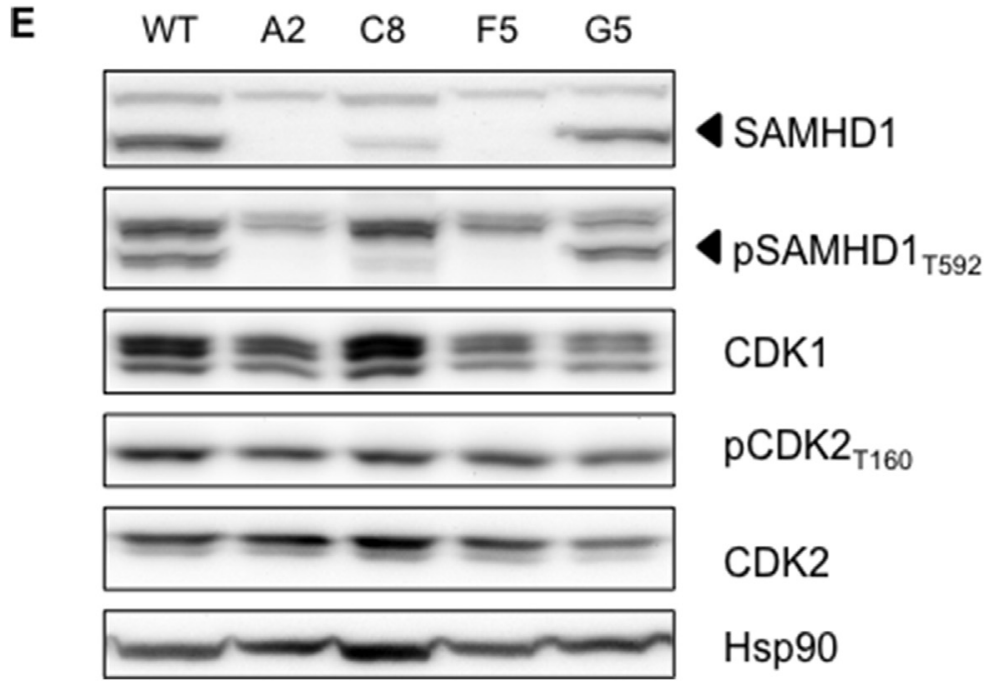

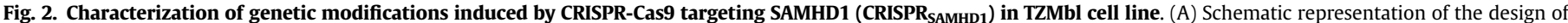

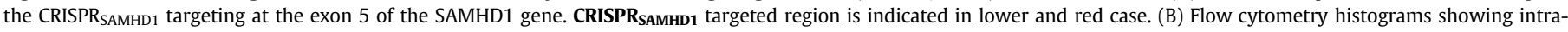

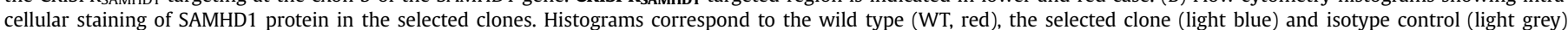

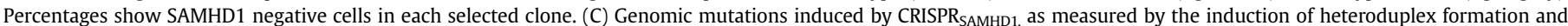


A

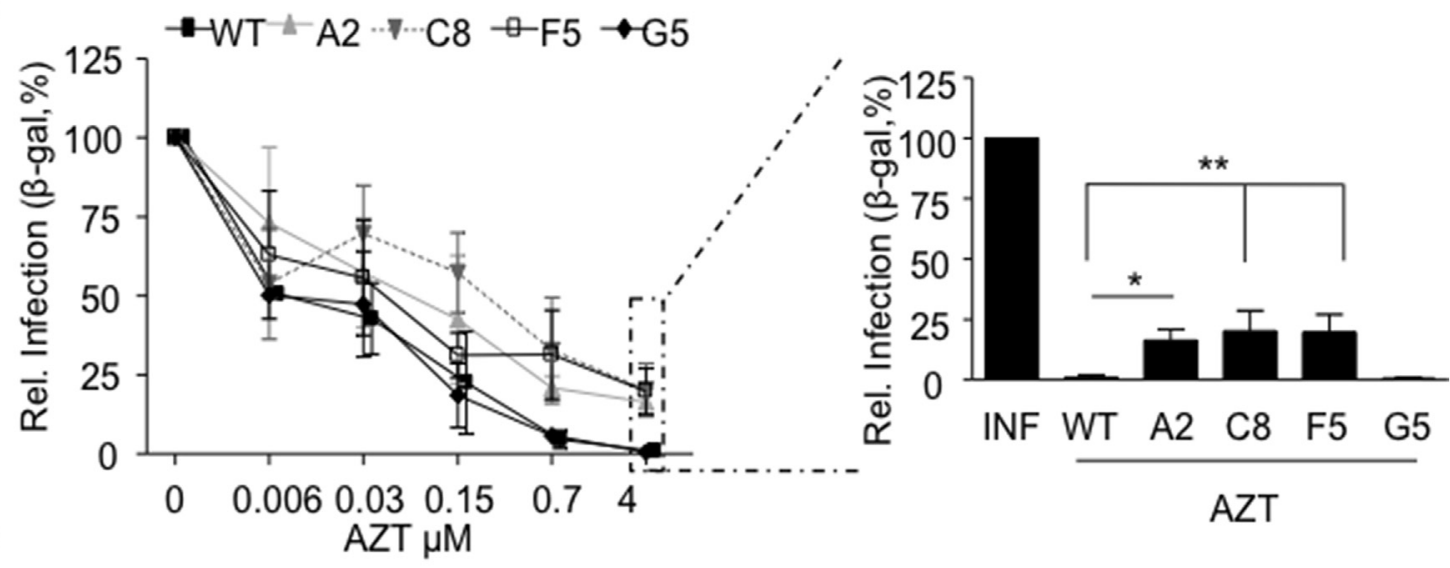

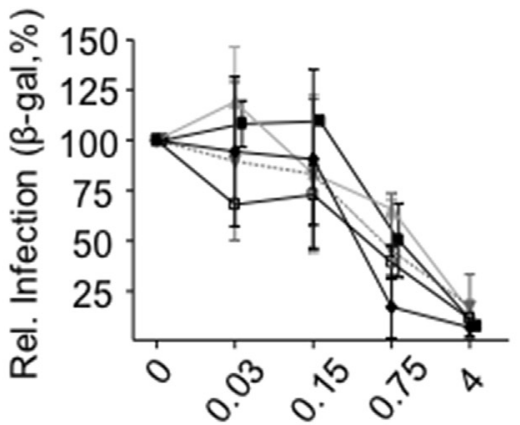

NVP $(\mu \mathrm{M})$

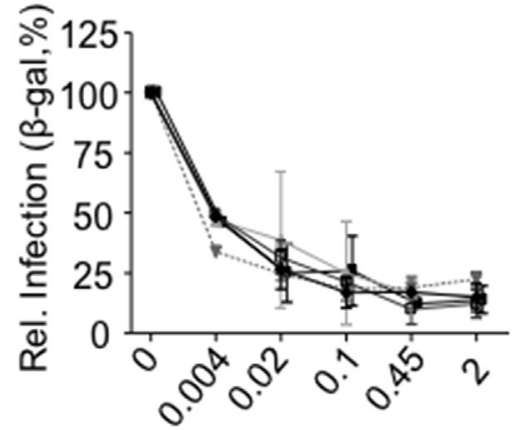

$\operatorname{RAL}(\mu \mathrm{M})$

C

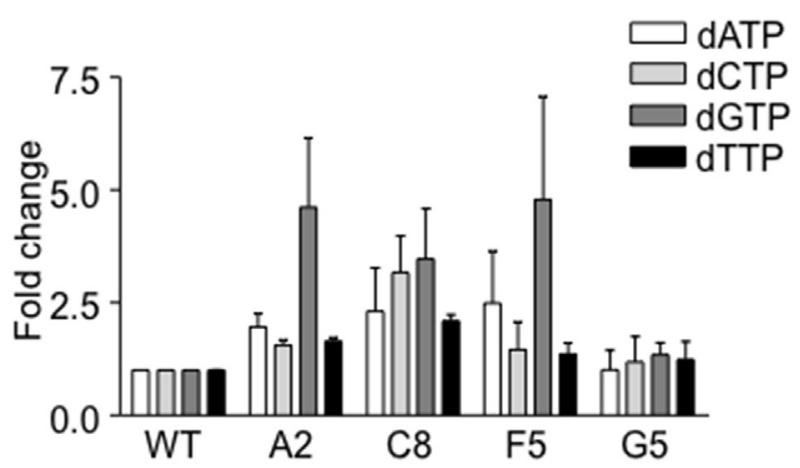

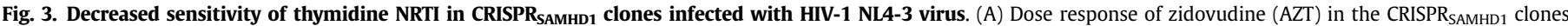

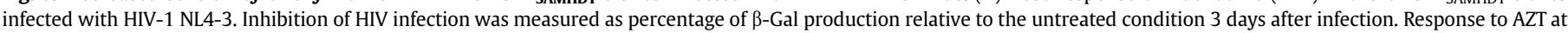

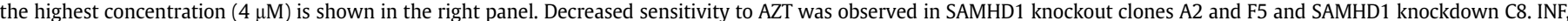

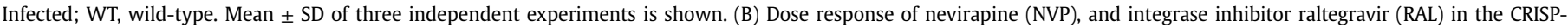

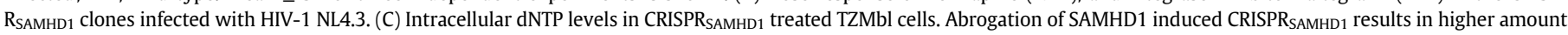
of intracellular dNTPs in clones A2, C8 and F5. Mean \pm SD of three independent experiments is shown. ${ }^{*} p<0.05 ;{ }^{* *} p<0.01$.

phosphorylation. Changes in overall phosphorylation of SAMHD1 were not visible in the mutant T592A probably due to the accumulation of phosphorylated sites on the N-terminal region of the protein (Fig. 4B). The specificity of SAMHD1 T592 phosphorylation measure was validated in PMA-treated THP-1 cells treated or not with phosphatase (Fig. 4C).

\subsection{SAMHD1 phosphorylation determined viral replication capacity}

To elucidate the role of phosphorylation sites in SAMHD1, clone F5 (SAMHD1 functional knockout) was selected to restore the expression of the wild-type form (pLPCX-SAMHD1-WT) and the

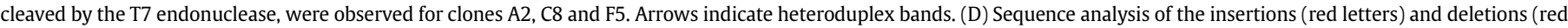

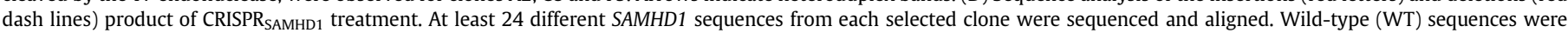

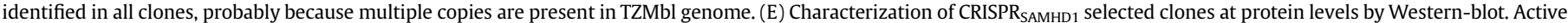

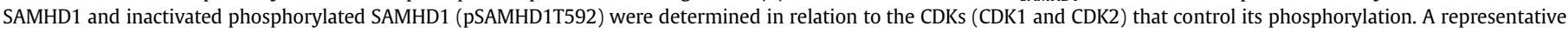

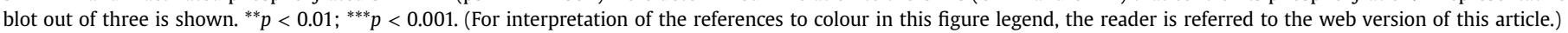


Table 1

Anti-HIV-1 activity of NRTI and NNRTI in SAMHD1 knockout cells.

\begin{tabular}{lllll}
\hline Compound & $\mathrm{EC}_{50} \mathrm{WT}$ & $\mathrm{EC}_{50}$ SAMHD1-KO & $\mathrm{FC}$ & $\mathrm{CC}_{50}$ \\
\hline AZT & $0.07 \pm 0.02$ & $0.26 \pm 0.1$ & 3.5 & $>4$ \\
d4T & $2.21 \pm 0.5$ & $7.19 \pm 3.18$ & 3.3 & $>5$ \\
3TC & $0.39 \pm 0.13$ & $0.54 \pm 0.16$ & 1.4 & $>1$ \\
ddC & $0.36 \pm 0.17$ & $0.47 \pm 0.07$ & 1.3 & $>1$ \\
TDF & $0.08 \pm 0.01$ & $0.26 \pm 0.15$ & 3 & $>10$ \\
ddI & $6.20 \pm 1.18$ & $18.9 \pm 0.89$ & 3 & $>25$ \\
ABC & $1.12 \pm 0.53$ & $6.03 \pm 2.83$ & 5.4 & $>25$ \\
EFV & $0.04 \pm 0.01$ & $0.06 \pm 0.03$ & 1.5 & $>0.3$ \\
NVP & $0.01 \pm 0.0001$ & $0.02 \pm 0.003$ & 2 & $>4$ \\
\hline
\end{tabular}

NRTI are AZT, d4T, 3TC, ddC, TFV, ddI, and ABC; NNRTI are NVP and EFV; EC50 and CC50 values were calculated in wild type(WT) or SAMHD1-negative TZMbl cells and expressed as $\mu \mathrm{M}$. EC50, effective concentration required to block HIV-1 replication by $50 \%$; CC50, Cytotoxic concentration 50 or needed concentration to induce $50 \%$ death of non-infected cells, evaluated with the MTT method; FC, fold change or ratio of the EC50 in WT cells and the EC50 in SAMHD1 negative cells. Results are the means \pm SD of three independent experiments. phosphorylation defective mutants (3T and T592A). Three days after transfection, cell extracts were obtained and analyzed by Western blot (Fig. 5A). Restoration of SAMHD1 expression was confirmed by the appearance of a band corresponding to total SAMHD1 for all transfected plasmids. Phosphorylated SAMHD1, measured with specific anti-pSAMHD1 at residue T592, was observed for SAMHD1-WT and the mutant 3T, but not for mutant T592A. No effects on protein expression were observed for CDK1, CDK2 or pCDK2 for any of the different re-expressed forms (Fig. 5A).

Activity of the different forms of SAMHD1 were evaluated by infection with HIV-1 NL4-3. As observed in MT-4 cells treated or not with $\mathrm{VLP}_{\mathrm{Vpx}}$, we did not observe significant differences in viral replication capacity between the SAMHD1-wt or the phosphorylation defective mutants 3T and T592A variants (Fig. 5B). Infection of wildtype TZMbl cells in the presence of AZT led to a complete block of HIV-1 viral replication (Fig. 5C). Conversely, infection of the SAMHD1 knockout F5 clone was clearly detectable. Transfection of

A

NLS

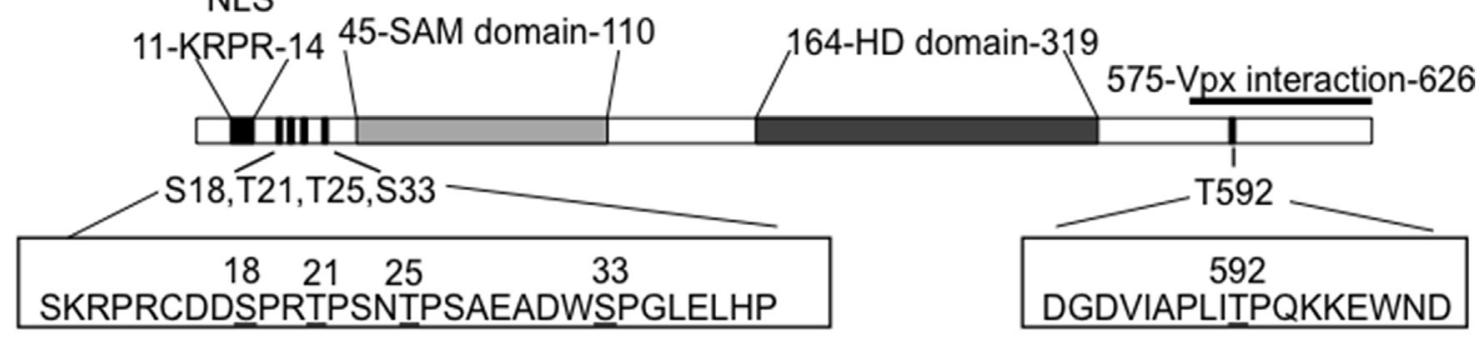

B

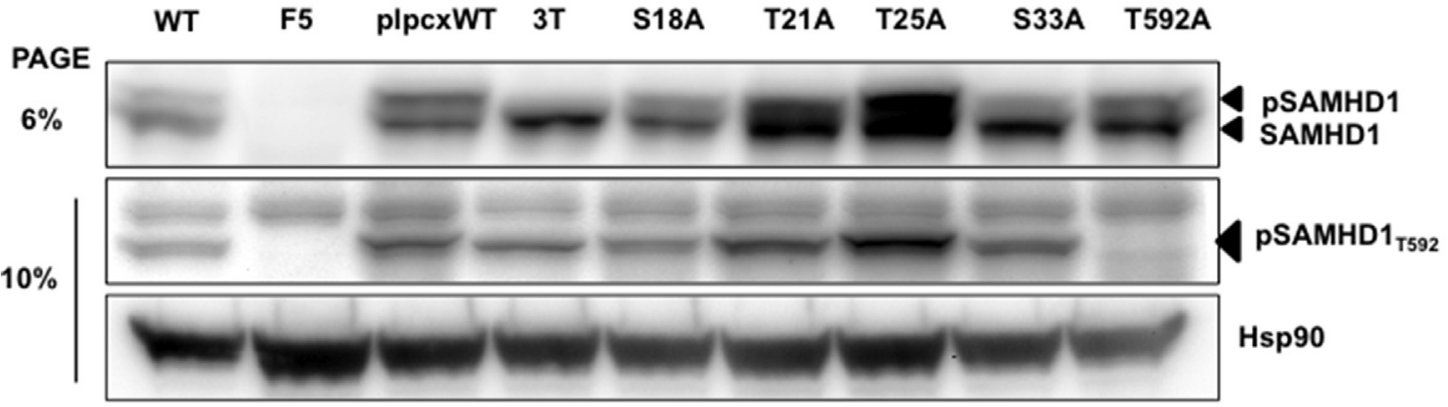

C
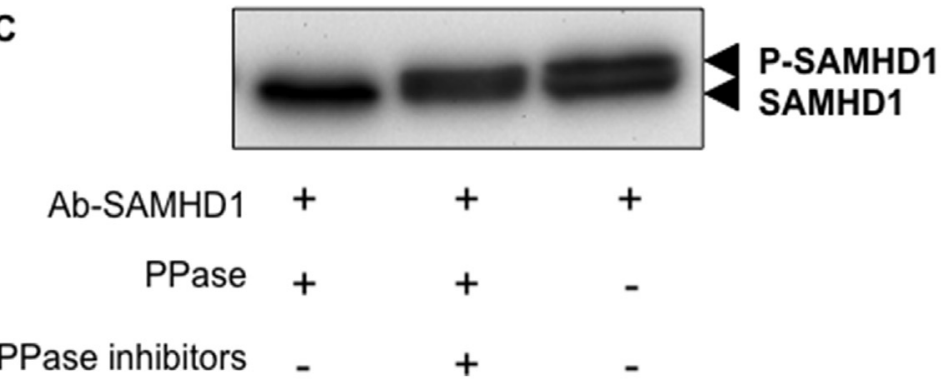

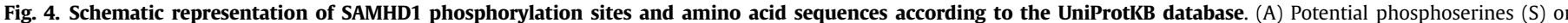

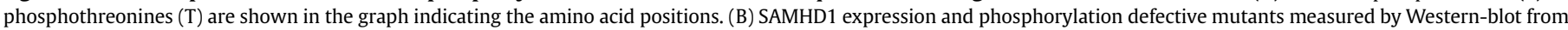

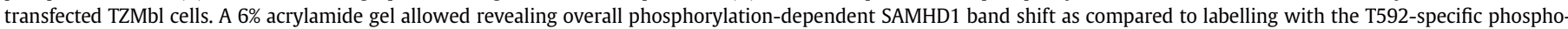

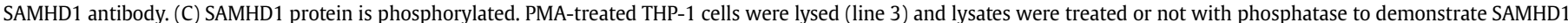
phosphorylation (lines 1 and 2). 
A

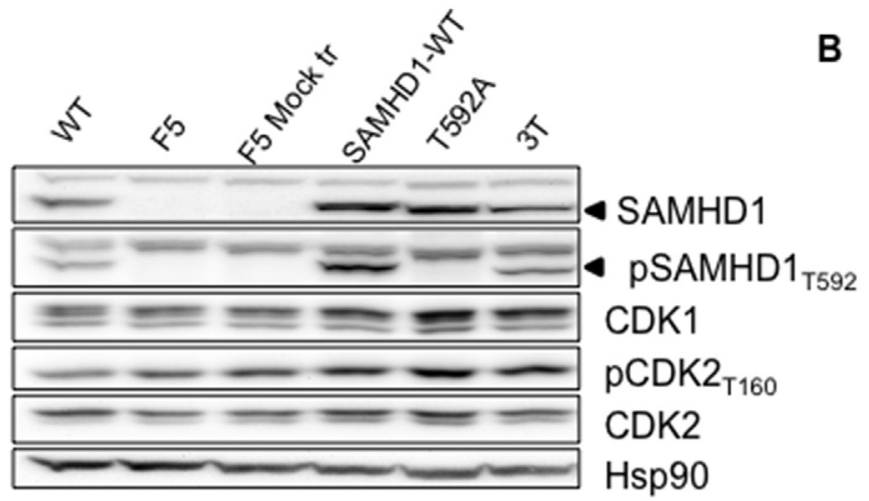

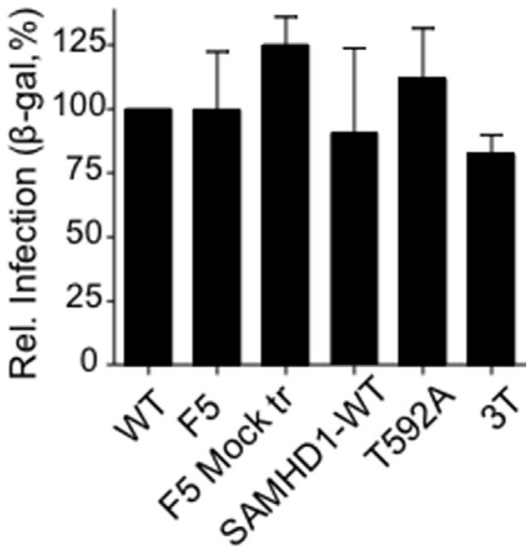

C

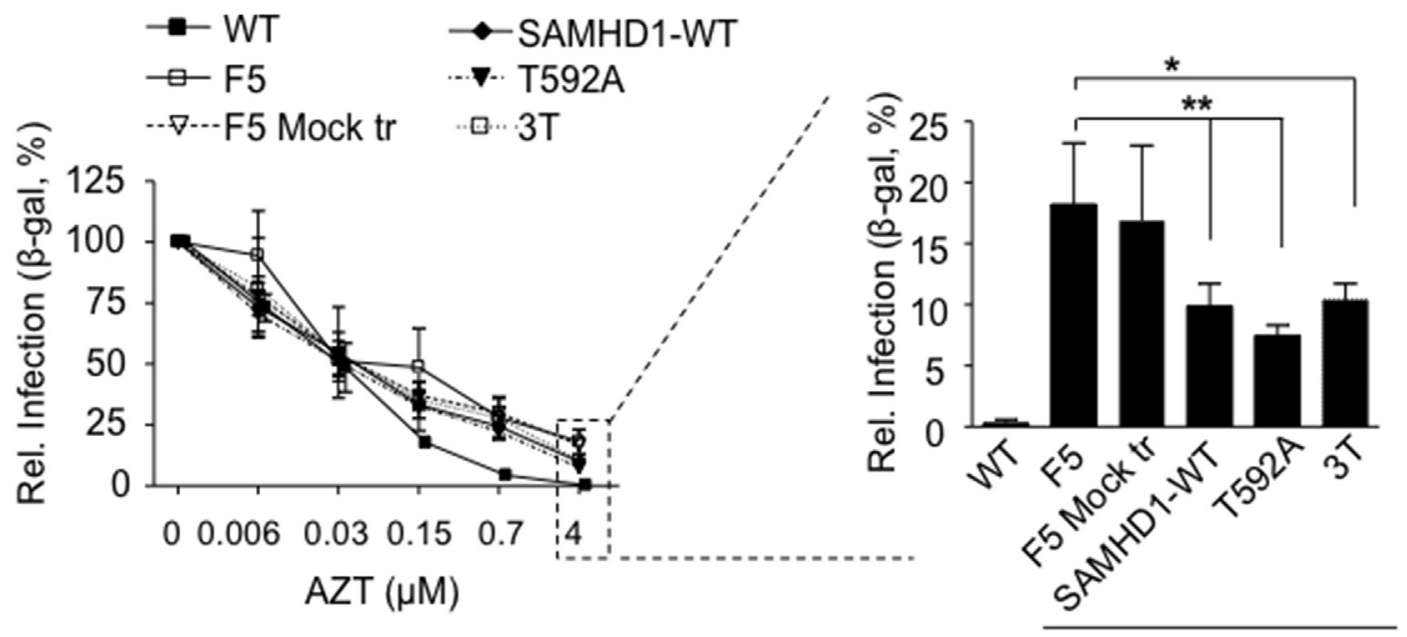

D

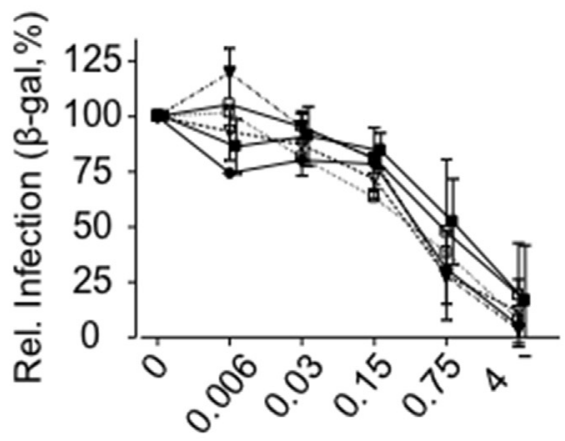

$\operatorname{NVP}(\mu \mathrm{M})$

AZT

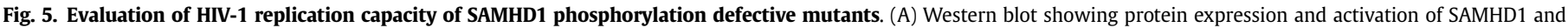

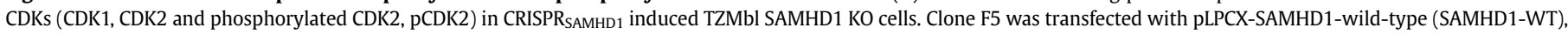

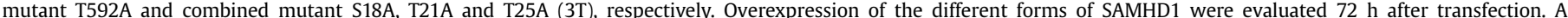

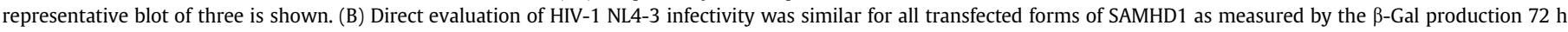

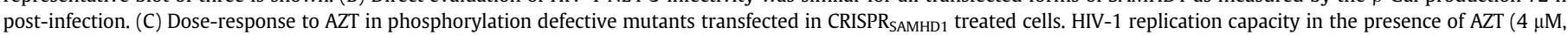

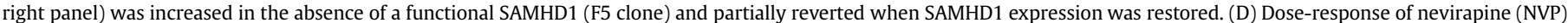

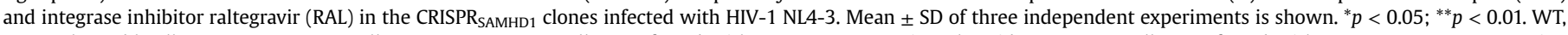

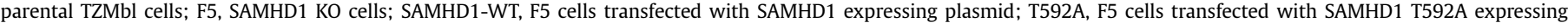
plasmid; 3T, F5 cells transfected with SAMHD1 N-terminal mutant expressing plasmid.

wt-SAMHD1 into F5 cells partially restored the block on HIV-1 replication. Similarly, expression of phosphorylation defective mutants T592A and 3T, induced a partial recovery of the sensitivity to AZT, between $89.3 \%$ and $92.2 \%$ compared to the F5 control cells. These partial effects may be related to limitations in the efficiency of the transfection of SAMH1 plasmids. No differences were 
observed in anti-HIV-1 potency for NVP or RAL for any of the phosphorylation variants of SAMHD1 (Fig. 5D). Loss of sensitivity to AZT due to active SAMHD1, as a result of lack of phosphorylation either in N-terminal (3T) or C-terminal (T592A), was confirmed with VSV-NL4.3-GFP virus (Fig. 6A and B) without affecting potency of NVP or RAL.

\subsection{Phosphorylation of SAMHD1 does not affect degradation of dATP in vitro}

To assess the in vitro activity of SAMHD1 related to its phosphorylation state, a plasmid SAMHD1-HA was overexpressed in HEK293 T cells and immunoprecipitated. Treatment with phosphatase lambda (PPase) resulted in the disappearance of the band corresponding to $\mathrm{p}$ (Thr)-Pro immunoblotting (Fig. 7A). Westernblot analysis was performed to determine the efficiency of overexpression, immunoprecipitation and phosphatase treatment (Fig. 7A). Assessment of dATP to ATP degradation in a timeresponse kinetics did not show differences between native
SAMHD1-HA (containing both active and inactive SAMHD1) or the fully active SAMHD1 (Fig. 7B).

\section{Discussion}

Biological activity of SAMHD1 is inherently linked to the control of entry and progression through the cell cycle (Pauls et al., 2014b; Sze et al., 2013b) and more recently associated to the protective immune responses tied to innate sensing of DNA (Herrmann et al., 2016; Sze et al., 2013b). Understanding how SAMHD1 is regulated and exerts its activity may not only be important for viral infections but also for determining the disease outcome of autoimmune diseases and cancer (Ballana and Este, 2015). Despite SAMHD1 apparent lack of effect on viral restriction in cycling cells, SAMHD1 is expressed and active, being important the generation of phosphorylated new models to fully elucidate the regulation and function of SAMHD1.

Genome editing has become an irreplaceable tool to provide new models to evaluate gain/loss of function of the targeted genes.
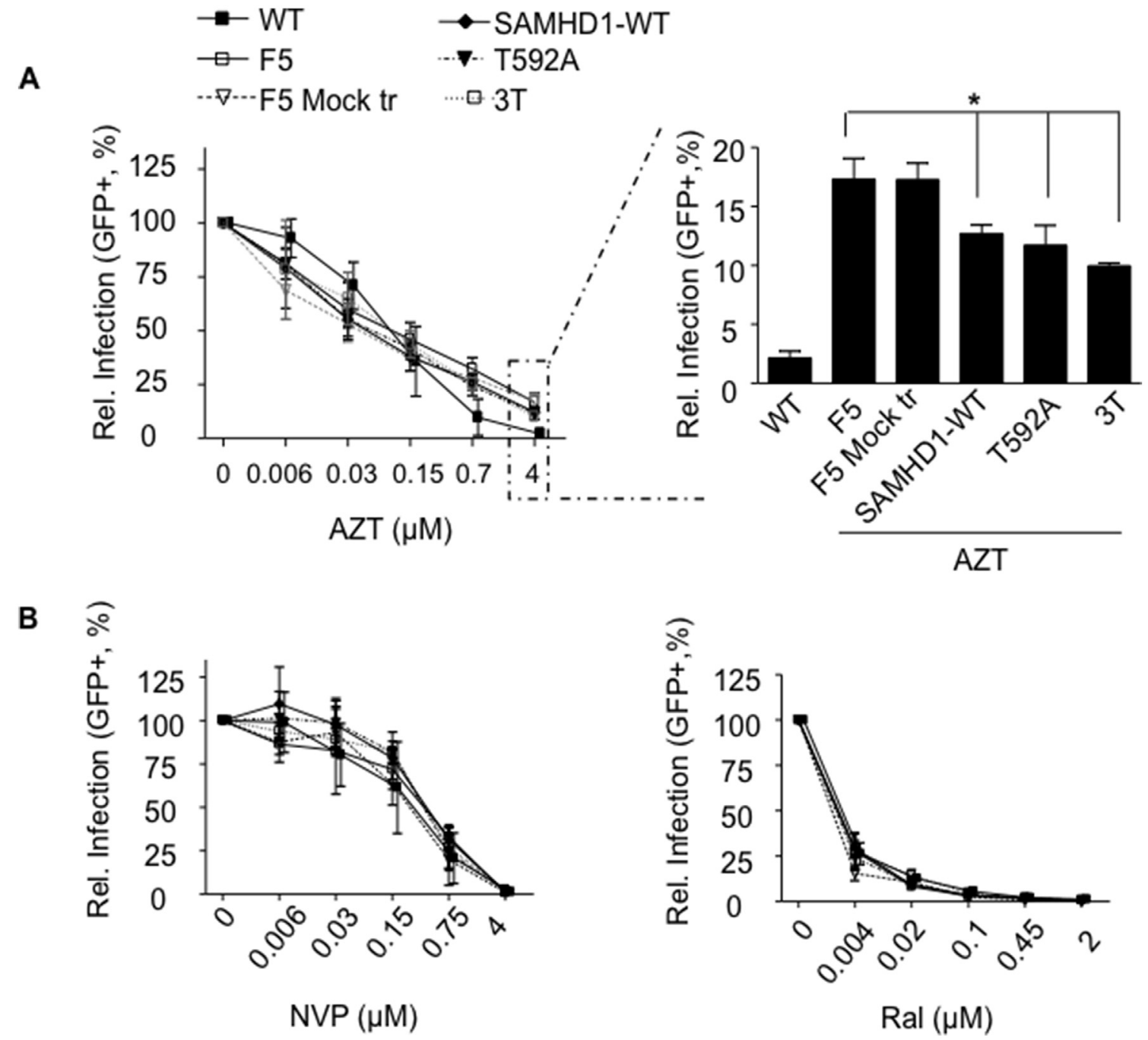

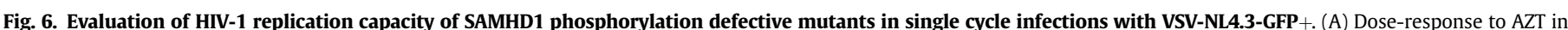

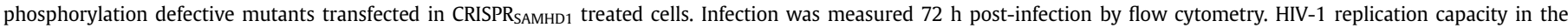

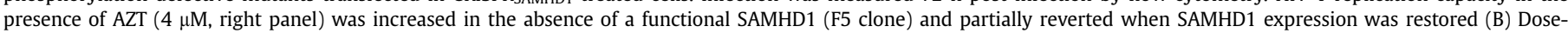

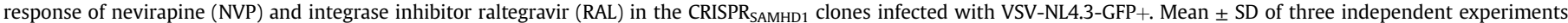

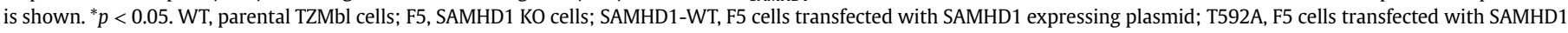
T592A expressing plasmid; 3T, F5 cells transfected with SAMHD1 N-terminal mutant expressing plasmid. 
A

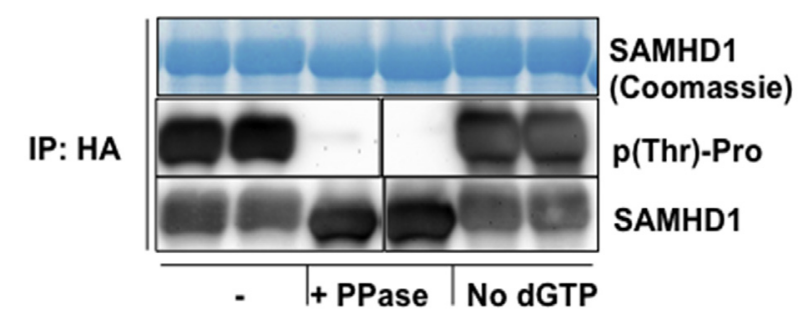

B

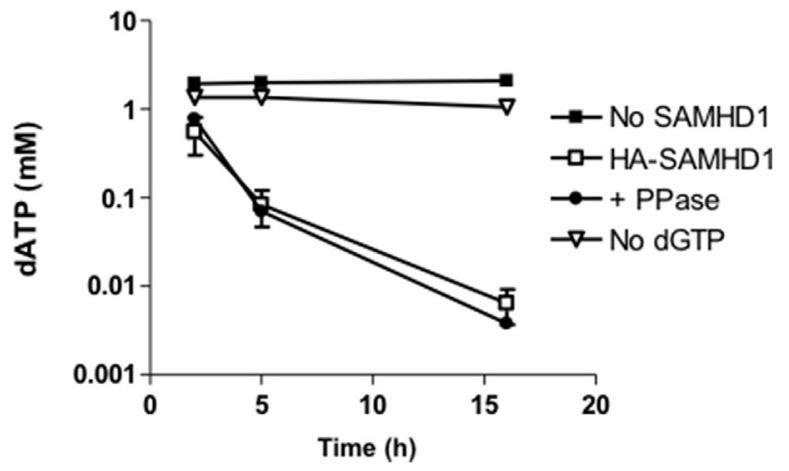

Fig. 7. In vitro evaluation of dNTPase activity of SAMHD1. (A) Assessment of SAMHD1 phosphorylation with or without phosphatase treatment measured by antiphospho(Thr)-Pro immunoblotting. PPase; Phosphatase activity. (B) Degradation of dATP to ATP was measured in immunoprecipitated SAMHD1-HA treated or not with phosphatase lambda at 0,5 and 16 h post-treatment. Samples without SAMHD1 or without dGTP (cofactor required for SAMHD1 hydrolase activity) were used as negative controls for dATP degradation overtime.

Here we generated a CRISPR-Cas9 system that successfully abrogated SAMHD1 expression, providing a new model to study the mechanisms underlying the regulation and function of SAMHD1.

SAMHD1 activity is regulated by cell-cycle dependent posttranslational modifications through cyclin-dependent kinase-mediated phosphorylation (Cribier et al., 2013; Pauls et al., 2014b; White et al., 2013b). Tight regulation exerted by CDKs on the SAMHD1 dNTPase activity is crucial for determining the availability of intracellular dNTPs, linking cell cycle and proliferation to a time opportunity for viral replication (Ballana and Este, 2015). Moreover, palbociclib a selective CDK4/6 inhibitor has been shown to inhibit SAMHD1 phosphorylation and to limit the intracellular dNTPs availability, resulting in a potent antiviral activity against (Pauls et al., 2014a) (Badia et al., 2016a).

Evaluation of viral replication capacity related to SAMHD1 restriction is only possible in a context where dNTP concentrations are below the threshold required for reverse transcription of the viral RNA genome into DNA (Laguette et al., 2011; Lahouassa et al., 2012) such as in primary cells. Consequently, in transformed cell lines such as MT-4 or TZMbl, where intracellular dNTP amounts are above the threshold for HIV-1 RT requirements, direct evaluation of viral replication capacity is not feasible even after SAMHD1 degradation. Our results confirmed that Vpx-induced SAMHD1 degradation in transformed cell lines exclusively affects viral sensitivity to nucleoside analogues but not to the NNRTI nevirapine, in agreement with previously published data for T cell lines and primary cells (Amie et al., 2013; Ballana et al., 2014; Huber et al., 2014). In addition, CRISPR SAMHD1 $_{1}$ treatment in TZMbl cells recapitulates the transient effect of Vpx by abrogating permanently the expression of SAMHD1 gene, in accordance to Bonifati et al., using CRISPR to knockout SAMHD1 in THP-1 cells (Bonifati et al.,

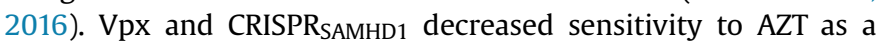

measure of viral replication capacity, as this is dependent of a competition between thymidine analogue (AZT) and the intracellular dNTPs for incorporation into newly transcribed viral DNA during the reverse transcription step. These results together with modified potency of other NRTIs including stavudine, tenofovir, didanosine or abacavir but not NNRTIs nevirapine nor efavirenz, reinforce the relevance of dNTPase activity of SAMHD1 as a mechanism for viral restriction and indicate that SAMHD1 may be functional even under conditions when its restrictive capacity is not apparent, such as in cycling cells with high dNTP levels. Presence of active forms of SAMHD1 in cycling cells is relevant since modulation of SAMHD1 expression using CRISPR-Cas9 technology has been shown to modify the sensitivity of the nucleoside analogue cytarabine in acute myelogenous leukemia (AML) (Herold et al., 2017; Schneider et al., 2017), defining modulation SAMHD1 as a new potential therapeutic strategy for malignancies related to the control of the intracellular dNTP content.

According to the structural domains described for SAMHD1 protein, we aimed at evaluation SAMHD1 phosphoylation sites. Although phosphorylation at T592 is widely accepted as indicative of SAMHD1 deactivation because SAMHD1 does not restrict HIV-1 in dividing cells where the protein is phosphorylated at residue T592 (Cribier et al., 2013; Pauls et al., 2014a; St Gelais et al., 2014; White et al., 2013a), the effect of this phosphorylation on SAMHD1 dNTPase activity is still unclear (Tang et al., 2015). The phosphomimetic mutants of SAMHD1 (T592E/T592D) have been proved to impair the ability to block HIV-1 infection in nondividing cells, but retained the ability to hydrolyze dNTPs in vitro and reduce the cellular dNTP levels (Welbourn et al., 2013; White et al., 2013b), a result that is confirmed by our evaluation of SAMHD1 function in vitro (Fig. 7). However Tang et al. (2015) show that phosphomimetic mutation T592E resulted in altered conformational changes, probably triggered by electrostatic repulsion, leading to SAMHD1-tetramer destabilization with a significant impairment of dNTPase activity. Arnold et al. (2015) also suggested that regulation of phosphorylation SAMHD1 alters its oligomeric state and its restriction capacity. Thus, enzymatic testing of SAMHD1 function may not recapitulate an adequate conformation as expressed in cell culture. In agreement, our data show that expression of the phosphorylation defective mutant T592A, sensitivity to AZT is partially recovered through a mechanism involving dNTPase activity and affecting viral replication capacity.

Interestingly, potential phosphorylation sites S18, T21, T25, S33 are located between the nuclear localization signal (NLS) and the SAM domain. Although the deletion of different regions of the $\mathrm{N}$ terminal sequence, including or not the SAM domain, have been shown to be nonessential for dNTPse activity, Vpx-recognition or Vpx-mediated degradation of SAMHD1 (Guo et al., 2013), the combination of three phosphorylation defective mutations at S18, T21 and T25 residues, modified the overall phosphorylation profile of SAMHD1. It has been described that SAMHD1 contains an additional nuclear targeting mechanism in addition to the classical nuclear localization signal KRPR, and that SAMHD1 nuclear accumulation is required for Vpx-induced degradation. In fact, N-terminal SAMHD1 deletion variants $(\Delta 2-41 ; \Delta 2-109)$ showed enhanced SAMHD1 import into the nucleus and became more sensitive to Vpx-mediated degradation (Guo et al., 2013). Since post-translational modifications, in particular phosphorylation, are key regulatory mechanisms for nuclear-cytoplasm pathways (Christie et al., 2016), it seems plausible to hypothesize that phosphorylation at the N-terminal region of SAMHD1 is implicated on its localization, affecting its activity and viral replication capacity. Further investigation should determine the role of phosphorylation of the N-terminal region of SAMHD1 and its effect on SAMHD1 activity. 
In summary, we describe how genome editing of SAMHD1 by CRISPR-Cas9 system provides a useful and stable SAMHD1 knockout model. In CRISPR-induced SAMHD1 knockout cells, assessment of viral replication linked to SAMHD1 phosphorylation is feasible in the context of elevated levels of intracellular dNTPs but in competition with the nucleotide analogues. Phosphorylation sites located in the N-terminal region of SAMHD1 (S18, T21, T25), in addition to residue T592, contribute to the overall phosphorylation.

\section{Acknowledgements}

We thank the National Institutes of Health (AIDS Research and Reference Reagent Program) and the EU Programme EVA Centralised Facility for AIDS Reagents, NIBSC, UK for reagents. This work was supported in part by the Spanish Ministerio de Economía y Competitividad (MINECO) project BFU2015-63800-R and BIO201348788-C2-1-R and Instituto de Salud Carlos III, Fondo de Investigación Sanitaria (FIS) PI13/01083, PI15/00492 and PI16/00103 cofinanced by FEDER. RB and EB are research fellows from FIS.

\section{References}

Amie, S.M., Daly, M.B., Noble, E., Schinazi, R.F., Bambara, R.A., Kim, B., 2013. Anti-HIV host factor SAMHD1 regulates viral sensitivity to nucleoside reverse transcriptase inhibitors via modulation of cellular deoxyribonucleoside triphosphate (dNTP) levels. J. Biol. Chem. 288, 20683-20691.

Antonucci, J.M., St Gelais, C., de Silva, S., Yount, J.S., Tang, C., Ji, X., Shepard, C., Xiong, Y., Kim, B., Wu, L., 2016. SAMHD1-mediated HIV-1 restriction in cells does not involve ribonuclease activity. Nat. Med. 22, 1072-1074.

Arnold, L.H., Groom, H.C., Kunzelmann, S., Schwefel, D., Caswell, S.J., Ordonez, P., Mann, M.C., Rueschenbaum, S., Goldstone, D.C., Pennell, S., Howell, S.A., Stoye, J.P., Webb, M., Taylor, I.A., Bishop, K.N., 2015. Phospho-dependent regulation of SAMHD1 oligomerisation couples catalysis and restriction. PLoS Pathog. 11, e1005194.

Badia, R., Angulo, G., Riveira-Munoz, E., Pujantell, M., Puig, T., Ramirez, C., TorresTorronteras, J., Marti, R., Pauls, E., Clotet, B., Ballana, E., Este, J.A., 2016a. Inhibition of herpes simplex virus type 1 by the CDK6 inhibitor PD-0332991 (palbociclib) through the control of SAMHD1. J. Antimicrob. Chemother. 71, 387-394.

Badia, R., Grau, J., Riveira-Munoz, E., Ballana, E., Giannini, G., Este, J.A., 2015. The thioacetate-omega(gamma-lactam carboxamide) HDAC inhibitor ST7612AA1 as HIV-1 latency reactivation agent. Antivir. Res. 123, 62-69.

Badia, R., Pauls, E., Riveira-Munoz, E., Clotet, B., Este, J.A., Ballana, E., 2014a. Zinc finger endonuclease targeting PSIP1 inhibits HIV-1 integration. Antimicrob. Agents Chemother. 58, 4318-4327.

Badia, R., Pujantell, M., Riveira-Muñoz, E., Puig, T., Torres-Torronteras, J., Martí, R., Clotet, B., Ampudia, R.M., Vives-Pi, M., Esté, J.A., Ballana, E., 2016b. The G1/S specific cyclin D2 is a regulator of HIV-1 restriction in non-proliferating cells. Plos Pathog. 12, e1005829 doi:1005810.1001371/journal.ppat.1005829.

Badia, R., Riveira-Munoz, E., Clotet, B., Este, J.A., Ballana, E., 2014b. Gene editing using a zinc-finger nuclease mimicking the CCR5Delta32 mutation induces resistance to CCR5-using HIV-1. J. Antimicrob. Chemother. 69, 1755-1759.

Baldauf, H.M., Pan, X., Erikson, E., Schmidt, S., Daddacha, W., Burggraf, M., Schenkova, K., Ambiel, I., Wabnitz, G., Gramberg, T., Panitz, S., Flory, E., Landau, N.R., Sertel, S., Rutsch, F., Lasitschka, F., Kim, B., Konig, R., Fackler, O.T., Keppler, O.T., 2012. SAMHD1 restricts HIV-1 infection in resting CD4(+) T cells. Nat. Med. 18, 1682-1687.

Ballana, E., Badia, R., Terradas, G., Torres-Torronteras, J., Ruiz, A., Pauls, E., RiveiraMunoz, E., Clotet, B., Marti, R., Este, J.A., 2014. SAMHD1 specifically affects the antiviral potency of thymidine analog HIV reverse transcriptase inhibitors. Antimicrob. Agents Chemother. 58, 4804-4813.

Ballana, E., Este, J.A., 2015. SAMHD1: at the crossroads of cell proliferation, immune responses, and virus restriction. Trends Microbiol. 23, 680-692.

Bonifati, S., Daly, M.B., St Gelais, C., Kim, S.H., Hollenbaugh, J.A., Shepard, C., Kennedy, E.M., Kim, D.H., Schinazi, R.F., Kim, B., Wu, L., 2016. SAMHD1 controls cell cycle status, apoptosis and HIV-1 infection in monocytic THP-1 cells. Virology 495, 92-100.

Brandariz-Nunez, A., Valle-Casuso, J.C., White, T.E., Laguette, N., Benkirane, M., Brojatsch, J., Diaz-Griffero, F., 2012. Role of SAMHD1 nuclear localization in restriction of HIV-1 and SIVmac. Retrovirology 9, 49.

Chen, Z., Zhu, M., Pan, X., Zhu, Y., Yan, H., Jiang, T., Shen, Y., Dong, X., Zheng, N., Lu, J. Ying, S., Shen, Y., 2014. Inhibition of Hepatitis B virus replication by SAMHD1. Biochem. Biophys. Res. Commun. 450, 1462-1468.

Christie, M., Chang, C.W., Róna, G., Smith, K.M., Stewart, A.G., Takeda, A.A., Fontes, M.R., Stewart, M., Vértessy, B.G., Forwood, J.K., Kobe, B., 2016. Structural biology and regulation of protein import into the nucleus. J. Mol. Biol. 428, 2060-2090

Cribier, A., Descours, B., Valadao, A.L., Laguette, N., Benkirane, M., 2013.
Phosphorylation of SAMHD1 by cyclin A2/CDK1 regulates its restriction activity toward HIV-1. Cell Rep. 3, 1036-1043.

Descours, B., Cribier, A., Chable-Bessia, C., Ayinde, D., Rice, G., Crow, Y., Yatim, A., Schwartz, O., Laguette, N., Benkirane, M., 2012. SAMHD1 restricts HIV-1 reverse transcription in quiescent CD4(+) T-cells. Retrovirology 9, 87.

Ducu, R.I., Dayaram, T., Marriott, S.J., 2011. The HTLV-1 tax oncoprotein represses Ku80 gene expression. Virology 416, 1-8.

Ferraro, P., Franzolin, E., Pontarin, G., Reichard, P., Bianchi, V., 2010. Quantitation of cellular deoxynucleoside triphosphates. Nucleic Acids Res. 38, e85.

Goldstone, D.C., Ennis-Adeniran, V., Hedden, J.J., Groom, H.C., Rice, G.I. Christodoulou, E., Walker, P.A., Kelly, G., Haire, L.F., Yap, M.W., de Carvalho, L.P., Stoye, J.P., Crow, Y.J., Taylor, I.A., Webb, M., 2011. HIV-1 restriction factor SAMHD1 is a deoxynucleoside triphosphate triphosphohydrolase. Nature 480, $379-382$.

Gonzalez-Vioque, E., Torres-Torronteras, J., Andreu, A.L., Marti, R., 2011. Limited dCTP availability accounts for mitochondrial DNA depletion in mitochondria neurogastrointestinal encephalomyopathy (MNGIE). PLoS Genet. 7, e1002035.

Gramberg, T., Kahle, T., Bloch, N., Wittmann, S., Mullers, E., Daddacha, W. Hofmann, H., Kim, B., Lindemann, D., Landau, N.R., 2013. Restriction of diverse retroviruses by SAMHD1. Retrovirology 10, 26.

Guo, H., Wei, W., Wei, Z., Liu, X., Evans, S.L., Yang, W., Wang, H., Guo, Y., Zhao, K. Zhou, J.Y., Yu, X.F., 2013. Identification of critical regions in human SAMHD1 required for nuclear localization and Vpx-mediated degradation. PLoS One 8, e66201.

Herold, N., Rudd, S.G., Ljungblad, L., Sanjiv, K., Myrberg, I.H., Paulin, C.B. Heshmati, Y., Hagenkort, A., Kutzner, J., Page, B.D., Calderon-Montano, J.M. Loseva, O., Jemth, A.S., Bulli, L., Axelsson, H., Tesi, B., Valerie, N.C., Hoglund, A., Bladh, J., Wiita, E., Sundin, M., Uhlin, M., Rassidakis, G., Heyman, M., Tamm, K.P., Warpman-Berglund, U., Walfridsson, J., Lehmann, S., Grander, D., Lundback, T., Kogner, P., Henter, J.I., Helleday, T., Schaller, T., 2017. Targeting SAMHD1 with the Vpx protein to improve cytarabine therapy for hematological malignancies. Nat. Med. 23, 256-263.

Herrmann, A., Happel, A.U., Gramberg, T., 2016. SAMHD1 in retroviral restriction and innate immune sensing - should we leash the hound? Curr. HIV Res. 14, $225-234$.

Hollenbaugh, J.A., Gee, P., Baker, J., Daly, M.B., Amie, S.M., Tate, J., Kasai, N., Kanemura, Y., Kim, D.H., Ward, B.M., Koyanagi, Y., Kim, B., 2013. Host factor SAMHD1 restricts DNA viruses in non-dividing myeloid cells. PLoS Pathog. 9, e1003481.

Hrecka, K., Hao, C., Gierszewska, M., Swanson, S.K., Kesik-Brodacka, M. Srivastava, S., Florens, L., Washburn, M.P. Skowronski, J., 2011. Vpx relieves inhibition of HIV-1 infection of macrophages mediated by the SAMHD1 protein. Nature 474 .

Huber, A.D., Michailidis, E., Schultz, M.L., Ong, Y.T., Bloch, N., Puray-Chavez, M.N. Leslie, M.D., Ji, J., Lucas, A.D., Kirby, K.A., Landau, N.R., Sarafianos, S.G., 2014 SAMHD1 has differential impact on the efficacies of HIV nucleoside reverse transcriptase inhibitors. Antimicrob. Agents Chemother. 58, 4915-4919.

Kim, E.T., White, T.E., Brandariz-Nunez, A., Diaz-Griffero, F., Weitzman, M.D., 2013. SAMHD1 restricts herpes simplex virus 1 in macrophages by limiting DNA replication. J. Virol. 87.

Kyei, G.B., Cheng, X., Ramani, R., Ratner, L., 2015. Cyclin L2 is a critical HIV dependency factor in macrophages that controls SAMHD1 abundance. Cell Host Microbe 17, 98-106.

Laguette, N., Sobhian, B., Casartelli, N., Ringeard, M., Chable-Bessia, C., Segeral, E. Yatim, A., Emiliani, S., Schwartz, O., Benkirane, M., 2011. SAMHD1 is the dendritic- and myeloid-cell-specific HIV-1 restriction factor counteracted by Vpx. Nature 474, 654-657.

Lahouassa, H., Daddacha, W., Hofmann, H., Ayinde, D., Logue, E.C., Dragin, L, Bloch, N., Maudet, C., Bertrand, M., Gramberg, T., Pancino, G., Priet, S., Canard, B. Laguette, N., Benkirane, M., Transy, C., Landau, N.R., Kim, B., MargottinGoguet, F., 2012. SAMHD1 restricts the replication of human immunodeficiency virus type 1 by depleting the intracellular pool of deoxynucleoside triphosphates. Nat. Immunol. 13, 223-228.

Landry, J.J., Pyl, P.T., Rausch, T., Zichner, T., Tekkedil, M.M., Stutz, A.M., Jauch, A. Aiyar, R.S., Pau, G., Delhomme, N., Gagneur, J., Korbel, J.O., Huber, W. Steinmetz, L.M., 2013. The genomic and transcriptomic landscape of a HeLa cell line. G3 (Bethesda) 3, 1213-1224.

Mangeot, P.E., Negre, D., Dubois, B., Winter, A.J., Leissner, P., Mehtali, M. Kaiserlian, D., Cosset, F.L., Darlix, J.L., 2000. Development of minimal lentivirus vectors derived from simian immunodeficiency virus (SIVmac251) and their use for gene transfer into human dendritic cells. J. Virol. 74, 8307-8315.

Pauls, E., Badia, R., Torres-Torronteras, J., Ruiz, A., Permanyer, M., Riveira-Munoz, E. Clotet, B., Marti, R., Ballana, E., Este, J.A., 2014a. Palbociclib, a selective inhibitor of cyclin-dependent kinase4/6, blocks HIV-1 reverse transcription through the control of sterile alpha motif and HD domain-containing protein-1 (SAMHD1) activity. AIDS 28, 2213-2222.

Pauls, E., Ballana, E., Este, J.A., 2013. Nucleotide embargo by SAMHD1: a strategy to block retroviral infection. Antivir. Res. 97, 180-182.

Pauls, E., Ruiz, A., Badia, R., Permanyer, M., Gubern, A., Riveira-Munoz, E., TorresTorronteras, J., Alvarez, M., Mothe, B., Brander, C., Crespo, M., MenendezArias, L., Clotet, B., Keppler, O.T., Marti, R., Posas, F., Ballana, E., Este, J.A., 2014b. Cell cycle control and HIV-1 susceptibility are linked by CDK6-dependent CDK2 phosphorylation of SAMHD1 in myeloid and lymphoid cells. J. Immunol. 193, 1988-1997.

Pauls, E., Ruiz, A., Riveira-Munoz, E., Permanyer, M., Badia, R., Clotet, B., Keppler, O.T., 
Ballana, E., Este, J.A., 2014c. p21 regulates the HIV-1 restriction factor SAMHD1. Proc. Natl. Acad. Sci. U. S. A. 111, E1322-E1324.

Pujantell, M., Badia, R., Ramirez, C., Puig, T., Clotet, B., Ballana, E., Esté, J.A., RiveiraMuñoz, E., 2016. Long-term HIV-1 infection induces an antiviral state in primary macrophages. Antivir. Res. 133, 145-155.

Rice, A.P., Kimata, J.T., 2015. Subversion of cell cycle regulatory mechanisms by HIV. Cell Host Microbe 17, 736-740.

Riveira-Munoz, E., Ruiz, A., Pauls, E., Permanyer, M., Badia, R., Mothe, B., Crespo, M., Clotet, B., Brander, C., Ballana, E., Este, J.A., 2014. Increased expression of SAMHD1 in a subset of HIV-1 elite controllers. J. Antimicrob. Chemother. 69, 3057-3060.

Ruiz, A., Pauls, E., Badia, R., Torres-Torronteras, J., Riveira-Munoz, E., Clotet, B. Marti, R., Ballana, E., Este, J.A., 2015. Cyclin D3-dependent control of the dNTP pool and HIV-1 replication in human macrophages. Cell Cycle 14, 1657-1665.

Ryoo, J., Choi, J., Oh, C., Kim, S., Seo, M., Kim, S.Y., Seo, D., Kim, J., White, T.E. Brandariz-Nunez, A., Diaz-Griffero, F., Yun, C.H., Hollenbaugh, J.A., Kim, B., Baek, D., Ahn, K., 2014. The ribonuclease activity of SAMHD1 is required for HIV1 restriction. Nat. Med. 20, 936-941.

Schaller, T., Goujon, C., Malim, M.H., 2012. AIDS/HIV. HIV interplay with SAMHD1. Science 335, 1313-1314.

Schneider, C., Oellerich, T., Baldauf, H.M., Schwarz, S.M., Thomas, D., Flick, R., Bohnenberger, H., Kaderali, L., Stegmann, L., Cremer, A., Martin, M., Lohmeyer, J., Michaelis, M., Hornung, V., Schliemann, C., Berdel, W.E., Hartmann, W., Wardelmann, E., Comoglio, F., Hansmann, M.L., Yakunin, A.F., Geisslinger, G., Strobel, P., Ferreiros, N., Serve, H., Keppler, O.T., Cinatl Jr., J., 2017. SAMHD1 is a biomarker for cytarabine response and a therapeutic target in acute myeloid leukemia. Nat. Med. 23, 250-255.

Seamon, K.J., Sun, Z., Shlyakhtenko, L.S., Lyubchenko, Y.L., Stivers, J.T., 2015. SAMHD1 is a single-stranded nucleic acid binding protein with no active site-associated nuclease activity. Nucleic Acids Res. http://dx.doi.org/10.1093/nar/gkv1633.

Simon, V., Bloch, N., Landau, N.R., 2015. Intrinsic host restrictions to HIV-1 and mechanisms of viral escape. Nat. Immunol. 16, 546-553.

Sommer, A.F.R., Rivière, L., Qu, B., Schott, K., Riess, M., Ni, Y., Shepard, C.,
Schnellbächer, E., Finkernagel, M., Himmelsbach, K., Welzel, K., Kettern, N., Donnerhak, C., Münk, C., Flory, E., Liese, J., Kim, B., Urban, S., König, R., 2016. Restrictive influence of SAMHD1 on Hepatitis B Virus life cycle. Sci. Rep. 6, 26616.

St Gelais, C., de Silva, S., Hach, J.C., White, T.E., Diaz-Griffero, F., Yount, J.S., Wu, L., 2014. Identification of cellular proteins interacting with the retroviral restriction factor SAMHD1. J. Virol. 88, 5834-5844.

Sze, A., Belgnaoui, S.M., Olagnier, D., Lin, R., Hiscott, J., van Grevenynghe, J., 2013a. Host restriction factor SAMHD1 limits human T cell leukemia virus type 1 infection of monocytes via STING-mediated apoptosis. Cell Host Microbe 14 422-434.

Sze, A., Olagnier, D., Lin, R., van Grevenynghe, J., Hiscott, J., 2013b. SAMHD1 host restriction factor: a link with innate immune sensing of retrovirus infection. J. Mol. Biol. 425, 4981-4994.

Tang, C., Ji, X., Wu, L., Xiong, Y., 2015. Impaired dNTPase activity of SAMHD1 by phosphomimetic mutation of Thr-592. J. Biol. Chem. 290, 26352-26359.

Welbourn, S., Dutta, S.M., Semmes, O.J., Strebel, K., 2013. Restriction of virus infection but not catalytic dNTPase activity is regulated by phosphorylation of SAMHD1. J. Virol. 87, 11516-11524.

White, T.E., Brandariz-Nunez, A., Valle-Casuso, J.C., Amie, S., Nguyen, L., Kim, B. Brojatsch, J., Diaz-Griffero, F., 2013a. Contribution of SAM and HD domains to retroviral restriction mediated by human SAMHD1. Virology 436, 81-90.

White, T.E., Brandariz-Nunez, A., Valle-Casuso, I.C., Amie, S., Nguyen, L.A., Kim, B., Tuzova, M., Diaz-Griffero, F., 2013b. The retroviral restriction ability of SAMHD1, but not its deoxynucleotide triphosphohydrolase activity, is regulated by phosphorylation. Cell Host Microbe 13, 441-451.

Wittmann, S., Behrendt, R., Eissmann, K., Volkmann, B., Thomas, D., Ebert, T. Cribier, A., Benkirane, M., Hornung, V., Bouzas, N.F., Gramberg, T., 2015. Phosphorylation of murine SAMHD1 regulates its antiretroviral activity. Retrovirology $12,1-15$.

Yan, J., Hao, C., DeLucia, M., Swanson, S., Florens, L., Washburn, M.P., Ahn, J., Skowronski, J., 2015. CyclinA2-Cyclin-dependent kinase regulates SAMHD1 protein phosphohydrolase domain. J. Biol. Chem. 290, 13279-13292. 